Florida International University FIU Digital Commons

6-19-2012

\title{
The Influence of Appearance-related Possible Selves on Disordered Eating
}

Aurelie Lucette

Florida International University, aurelie.lucette@gmail.com

DOI: $10.25148 /$ etd.FI12073003

Follow this and additional works at: https://digitalcommons.fiu.edu/etd

\section{Recommended Citation}

Lucette, Aurelie, "The Influence of Appearance-related Possible Selves on Disordered Eating" (2012). FIU Electronic Theses and Dissertations. 679.

https://digitalcommons.fiu.edu/etd/679

This work is brought to you for free and open access by the University Graduate School at FIU Digital Commons. It has been accepted for inclusion in FIU Electronic Theses and Dissertations by an authorized administrator of FIU Digital Commons. For more information, please contact dcc@fiu.edu. 


\title{
FLORIDA INTERNATIONAL UNIVERSITY
}

\author{
Miami, Florida
}

\section{THE INFLUENCE OF APPEARANCE-RELATED POSSIBLE SELVES ON DISORDERED EATING}

\author{
A thesis submitted in partial fulfillment of the \\ requirements for the degree of \\ MASTER OF SCIENCE \\ in \\ PSYCHOLOGY \\ by
}

Aurelie Lucette

2012 
To: $\quad$ Dean Kenneth G. Furton

College of Arts and Sciences

This thesis, written by Aurelie Lucette, and entitled the Influence of Appearance-Related Possible Selves on Disordered Eating, having been approved in respect to style and intellectual content, is referred to you for judgment.

We have read this thesis and recommend that it be approved.

$\begin{array}{r}\hline \text { Fatma G. Huffman } \\ \hline \text { Dionne P. Stephens } \\ \hline \text { Leslie D. Frazier, Major Professor }\end{array}$

Date of Defense: June 19, 2012

The thesis of Aurelie Lucette is approved.

Dean Kenneth G. Furton
College of Arts and Sciences

Dean Lakshmi N. Reddi
University Graduate School

Florida International University, 2012 


\section{ACKNOWLEDGMENTS}

Working on my thesis over the last year has been a truly meaningful experience, as I started an academic and personal journey in the United States. I would like to gratefully and sincerely thank Dr. Leslie Frazier for her continuous guidance, supervision, and kind understanding from the very early stages of the study. Her dedication and passion are an inspiration to me as I begin my new journey into a doctoral program. I gratefully acknowledge my committee members, Dr. Stephens and Dr. Huffman, and Dr. Arango, for their precious advice and encouragement throughout the work. Many thanks go to Alina Nazareth, Christopher Silva, Jasmine Villacis, Allyson Timmons, and Tracey Robinson for their assistance with data collection. I am also very grateful to Dr. Paulette Johnson and Alejandra Matamala for their patience and guidance with statistical analyses. 


\section{ABSTRACT OF THE THESIS \\ THE INFLUENCE OF POSSIBLE SELVES ON DISORDERED EATING \\ by}

Aurelie Lucette

Florida International University, 2012

Miami, Florida

Professor Leslie D. Frazier, Major Professor

This study explores the potential relationship between disordered eating and appearance-related possible selves. The sample consisted of 293 female college students (mean age $=22$ ). Participants were administered interviews consisting of demographic information, the Possible Selves Interview, the Eating Attitudes Test-26, The Physical Self Description Questionnaire, and the Rosenberg Self-Esteem Scale. More than half of the participants reported an appearance-related possible self $(n=154)$. As expected, disordered eating scores were found to be higher for participants who reported an appearance-related possible self: $t(288)=-3.04, p<.005$. Findings reiterate that different constructs within the self-concept are proximal motivators for eating behaviors. The present study provides information for future research to explore the influence of possible selves on eating behaviors in women with eating disorders. 


\section{TABLE OF CONTENTS}

CHAPTER

PAGE

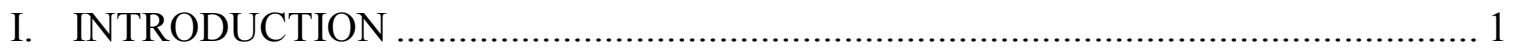

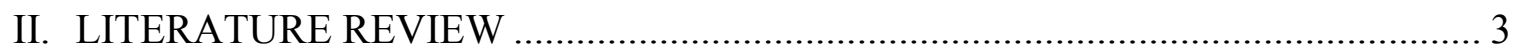

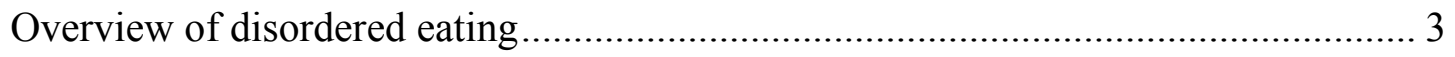

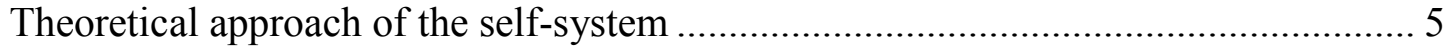



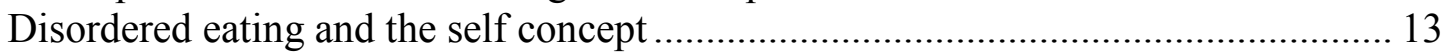

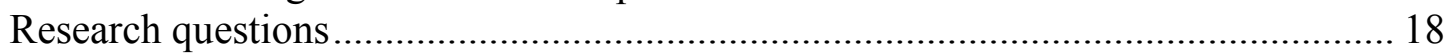

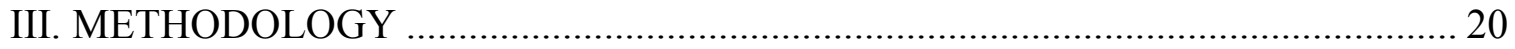

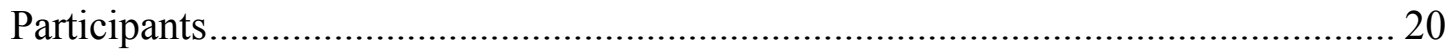

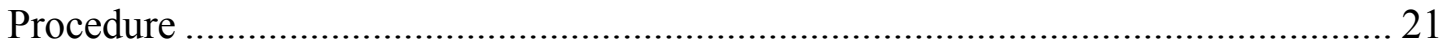

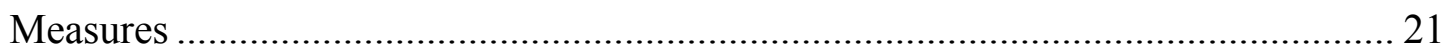

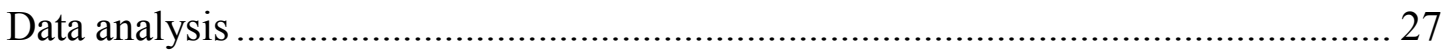



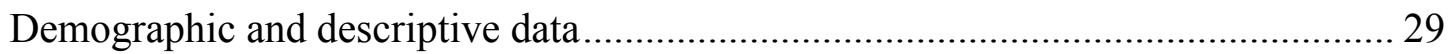

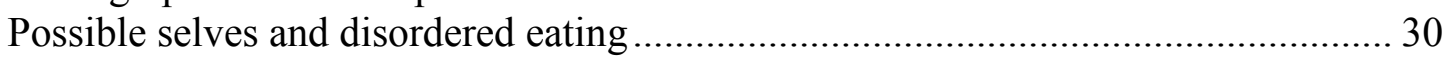

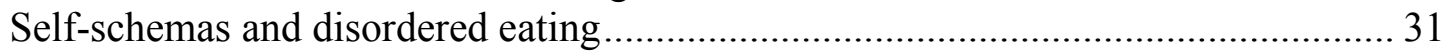

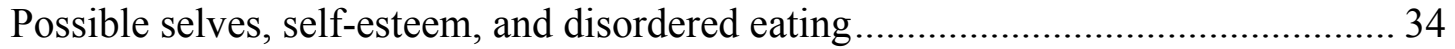

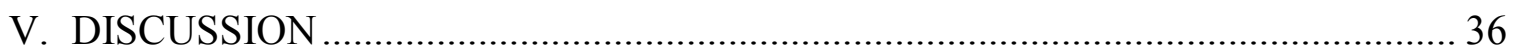

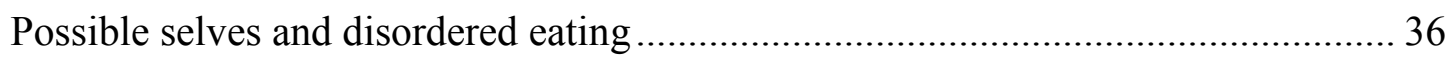

Influence of the self-concept on disordered eating ............................................. 37

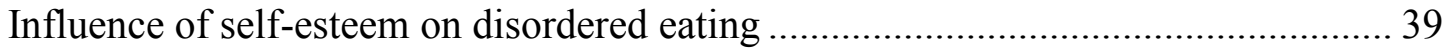

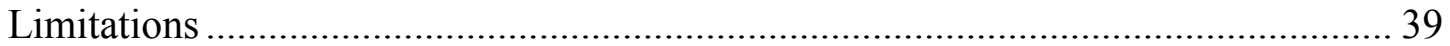



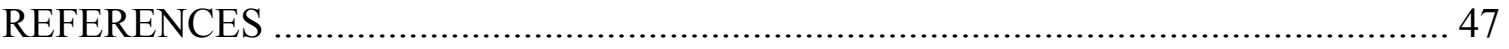

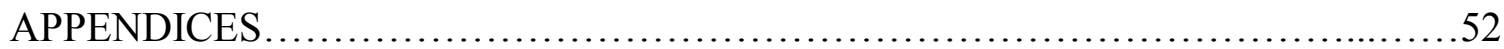




\section{CHAPTER I}

\section{INTRODUCTION}

In Western countries, the unhealthy eating behaviors that permeate the society have received considerable attention from researchers across disciplines. In the last decades, the influence of self-representations on behaviors has emerged as a focal point in an attempt to shed some light on the development and maintenance of pervasive disordered eating and weight control habits. Constructs such as self-concept and selfesteem have gained attention and generated important research findings. However, research has yet to determine the role of possible selves on women's eating behaviors. Possible selves are future-oriented representations of the self, both positive and negative, that motivate behaviors (Markus \& Wurf, 1987). As such, they may play a pivotal role in the engagement of disordered eating behaviors and influence body image.

The present study endeavors to understand disordered eating, encompassing clinical eating disorders and subclinical symptoms, by exploring the appearance-related possible selves of college women. Future-oriented perceptions and expectations hold a critical role in motivating actions, and their influence on one's current behaviors towards eating will be explored in this study. Furthermore, it is necessary to consider the selffeelings attached to one's self-perceptions when assessing the conceptual link between self-cognition and motivation (Markus \& Nurius, 1986). Indeed, the activation of a possible self triggers specific affects related to self-esteem, which in turn have the potential to influence the shape and content of one's behaviors. Consequently, careful 
consideration will be given to the impact of self-esteem on the relationship between appearance-related possible selves and disordered eating. 


\section{CHAPTER II}

\section{LITERATURE REVIEW}

\section{Overview of disordered eating}

In western countries, the lifetime prevalence of major eating disorders, Anorexia Nervosa and Bulimia Nervosa, have been reported to range between $0.3 \%$ and $0.9 \%$, and $1.0 \%$ and $1.5 \%$ of the general population, respectively (Hoek \& Van Hoeken, 2003; Hudson, Hiripi, Pope, \& Kessler, 2007). In addition, as much 3.5\% of women reported having a binge eating disorder at some point in their lives (Hudson, Hiripi, Pope, \& Kessler, 2007). Currently, the DSM-IV-TR (2000) offers a thorough classification of eating disorders, nonetheless they remain complex to classify as their core symptoms range along a continuum of severity. On the basis of the criteria established by the American Psychiatric Association (2000), as many as $8 \%$ to $15 \%$ of late adolescent and adult women will experience significant subclinical symptoms of eating disorders at some point in their lives (Hoek, 2006; Touchette, Henegar et al., 2011). An early study reported that as much as one third of undergraduate college women experienced some intermediate form of disordered eating (Mintz \& Betz, 1998). Overall, negative attitudes about weight and shape and unhealthy approaches to weight control are salient in women without eating disorders between the age of 25 and 45 (Reba-Harrelson, Von Holle, Hamer, Swann, Reyes, \& Bulik, 2009). Consequently, it has been proposed that affective symptomatology might be critical for differentiating between clinical eating disorders and less severe or subclinical variants (Garner, Olmsted, Polivy, \& Garfinkel, 1984; Laessle, 
Tuschl, Waadt, \& Pirke, 1989; Stice \& Agras, 1999). Given the frequencies of both subclinical and clinical behavioral manifestations of eating disorders in the young adult female population, empirical studies must clearly define and operationalize what they attempt to examine. Thus, in the present study we will refer to "disordered eating," an operational definition that accounts for not only the symptoms found in clinical eating disorders but also the diversity of subclinical symptoms that are increasingly posing a significant threat to women's health, well being and overall quality of life.

Dieting may have entered our daily vocabulary as a seemingly straightforward word; however, the repertoire of behaviors it covers is actually quite intricate, as dieting refers to a wide array of practices directed toward weight regulation. Advertised through popular culture and the media, are countless diets with alluring names that carry irresistible promises to lose weight. Nonetheless, most of them entail unhealthy behaviors. In the last decades, dieting has been associated a significant increase in a variety of symptoms and greater severity of eating disorders, especially in college women who are experiencing, emotional distress (Ackard, Croll, \& Kerney-Cooke, 2002; Jacobi, Hayward, De Zwaan, Kraemer, \& Agras, 2004; Keel, Baxter, Heatherton, \& Joiner, 2007). Moreover, despite falling into a normal weight range, numerous women report a desire to be thinner and/or to lose weight (Fallon \& Rozin, 1985; Grigg, Bowman, \& Redman, 1996; Miller \& Halberstardt, 2005; Vohs, Heatherton, \& Herrin, 2001). As many as $74 \%$ of women ages 25 to 45 reported that their concerns about shape and weight were interfering with their happiness (Reba-Harrelson et al., 2009). As a result, regardless of their actual body weight, many college women engage in dieting behaviors 
(Berg, Frazier, \& Sherr, 2009; Krahn, Kurth, Gomberg, \& Drewnowski, 2005), especially non-purging compensatory behaviors such as excessive exercise (Grigg et al., 1996).

The research on disordered eating is abundant and always growing; to date, however, no consensus has been reached regarding the risk factors involved in its etiology (Jacobi et al., 2004; Stice, 2002). Disordered eating has been consistently revealed as a very complex and multifaceted pathology. Numerous factors have been highlighted as having an influence in its development and maintenance, and yet, their role is still debated. Recently however, the self-system has offered an interesting avenue to understand the development of disordered eating.

\section{Theoretical approach of the self-system}

Beyond our awareness of existing as separate entities in the world, every one of us develops awareness into the way we see ourselves, including perceptions about our unique personality traits, physical appearance, competences, roles. The self-system is a rich multifaceted system that includes the self-concept, self-schemas, self-esteem, possible selves, and other self-perceptions concepts. From a very early age we accumulate knowledge about ourselves that is fundamental to the way we interact with our environment as it provides directions to our behaviors.

As part of the self-system, the self-concept forms a crucial cognitive structure (Cantor \& Kihlstrom, 1987; Markus \& Wurf, 1987) that provides a framework to give meaning to one's thoughts, feelings, values, and actions. In addition, the self concept influences goal-directed behaviors by providing incentives, plans, rules, and 
consequences for one's actions (Markus \& Herzog, 1992). As stated by Franken (1994, p. 443) "there is a great deal of research which shows that the self concept is, perhaps, the basis for all motivated behavior. It is the self concept that gives rise to possible selves, and it is possible selves that create the motivation for behavior." Early definitions in which the self concept was identified as a monolithic and stable structure have evolved over time, and it is now largely accepted as a dynamic and multifaceted construct, which encompasses not only our perceptions of the here and now but also who we could be in the future (Markus \& Nurius, 1986).

Within the self concept, self-schemas are complex organizations of knowledge about the self in a specific behavioral domain that play a role in the motivation and regulation of goal-directed behaviors (Markus, 1977). Self-schemas have been conceptualized as a knowledge structure that reflects a domain of behavioral and emotional commitment (Stein \& Corte, 2007), such as body weight (Markus, Hamill, \& Sentis, 1987; Stein \& Corte, 2007) or exercise (Kendzierski, 1988). Self-schemas can be further construed as the cognitive product of our interactions with the social environment (Cantor \& Kihlstrom, 1987; Markus, 1977). In turn, those cognitive structures shape one's interactions with the social world by directing our attention to information relevant to a self-schema which is contained in our repertoire (Markus, 1977). Thus it follows that if body weight schemas are shared by a majority of people, individuals differ regarding the extent to which they will process weight-related information (Markus, Hamill, \& Sentis, 1987). Therefore, physical and, more specifically, appearance self-schemas will 
vary in importance and complexity across individuals and they will impact their behaviors and attitudes in different ways.

Research on possible selves. As stated earlier, the self-concept represents an interface between what was before, what might be in the future, and what is now (Cross \& Markus, 1991). Within that framework, possible selves are a type of self-schemas that embody representations of one's self in the future. Specifically, they are future selfrepresentations, both hoped for and feared, that have a motivational influence on one's sense of self and behaviors (Markus \& Nurius, 1986). Possible selves are not vague ideas of what could be, on the contrary, they are specific and well-articulated images, visions, if you will, of the self at different stages of development projected into the future. Possible selves are individually unique conceptions that reflect all the developmentally and contextually relevant information that is absorbed into the self-concept.

Possible selves have valence and give direction and meaning to one's hopes and fears. "An individual's repertoire of possible selves can be viewed as the cognitive manifestations of enduring goals, aspirations, motives, fears, and threats" (Markus \& Nurius, 1986). The individual alone gives life to his/her representations and therefore creates his/her own developmental path, adjusting to the changing opportunities and environmental contexts (Frazier \& Hooker, 2006). Since possible selves are often private and primarily defined by the individual, they can be modified and assume new forms easily (Cross \& Markus, 1991). However, even if private and individually personalized, possible selves are influenced by one's social environment from which social comparisons to salient others are drawn: "What others are now, I could become" (Markus 
\& Hazel, 1986). Despite the far-reaching and unique nature of the possible selves that individuals construct, research consistently demonstrates that they are closely tied to the sociocultural and historical environment one is embedded in (Frazier \& Hooker, 2006). Thus, the sociocultural influences found in the media, peer culture, and gender-related values will therefore influence the modeling of possible selves.

Possible selves as motivators of behavior. Exploring possible selves is crucial as they hold important functions that can help us understand how individual behaviors are articulated within the self-concept. First, possible selves serve as incentives for future behaviors. By providing well-elaborated sense or image of the anticipated vision of self, possible selves allow more instrumental action in the direction of the hoped-for possible selves or against feared possible selves. For example, a woman may have developed images of herself as being overweight when she reaches 50 year-old. That possible self might motivate her to go to the gym late at night after a long day of work, or to systematically order salad when she goes to a restaurant. As stated by Cross \& Markus (1991), "from an adult development perspective, possible selves are the blueprints for personal change and growth across the life span". These future-oriented representations help with the organization of one's actions and adaptation to new roles and changing constraints across the life span by selecting relevant information in pursuit of the possible selves. More specifically, self-directed behaviors are influenced by possible selves through self-regulatory processes that are associated to them. These self-regulatory processes, self-efficacy and outcome expectancy, are cognitive expectations enacted to help achieve or stay away from certain selves in the future. They further determine the 
actions, plans, and behaviors that help one reach his or her possible selves (Bandura, 1989; Frazier \& Hooker, 2006; Markus \& Ruvolo, 1989).

Taking a step forward, researchers have propounded that balance within selfdomains is critical as it enable maximal effectiveness (Frazier \& Hooker, 2006; Markus \& Ruvolo, 1989; Oyserman \& Markus, 1988). In other words, a positive possible self will be a greater motivational resource if counterbalanced by a negative self in the same domain. Recall our example: A woman's feared possible-self of "being overweight" might be activated in her working self-concept. However, her fear would be more likely to lead her into inaction if not balanced by a self-representation of a positive outcome such as "being a thin and happy woman." Indeed, bringing the negative self alone in the working self-concept might prompt an individual into disorganized behaviors and create negative affects whether it could be offset by deploying as well a positive possible self that would increase the array of motivational resources and therefore lead to better effectiveness. The concept of balance, however, needs to be further examined in clinical research before definitive conclusions can be reached.

The interpretative framework of possible selves. A second function of possible selves is to provide a context for evaluation and appraisal of the current self. In other words, the significance attached to a given event in the "here and now" will largely depend on the realm of possibilities envisioned by an individual. Gaining three pounds might hold more significance for a woman who is afraid of being overweight when she reaches 50 years-old and prompt more distress than for one of her friends who does not picture herself as overweight in the future. On the basis of the significance attached to 
that possible self and on the degree to which they are associated to strongly elaborated images and conceptions (Markus \& Ruvolo, 1989), they can urge an individual to behave in specific ways. Among individuals, the strength of self-regulatory processes attached to a possible self will vary tremendously. Ultimately, individuals who believe that an outcome is attainable and likely to become a reality are more likely to endorse behaviors leading to the desired goal - or keeping them away from the feared outcome. Selfefficacy and outcome expectancy are indeed critical self-regulatory processes involved in behavior control (Hooker \& Kaus, 1992).

To further understand how possible selves might motivate behavior, we need to delve into the central self-regulatory process attached to those representations. Markus \& Nurius (1986) argued that beliefs about efficacy are especially significant when they are linked to well-elaborated possible selves. Perceived self-efficacy, or the perception of one's own ability to perform well a task or a behavior, is deemed critical in motivating behaviors toward a desired goal (Bandura, 1989). Hooker and Kaus $(1992,1994)$ found that perceived self-efficacy for hoped-for and feared possible selves was a strong predictor of engaging in health behaviors.

In the realm of research on eating disorders, feeling of inefficacy has been associated with dieting frequency (Ackard, Croll, Kearney-Cooke, 2002) as well as symptoms of eating pathology (Cooley \& Toray, 1996). More recently, Berman (2006) observed that adults reporting lower scores on a measure of eating self-efficacy - one's ability to control eating - when dealing with negative emotions or when abundance of food was available experienced more weight preoccupation, feeling of ineffectiveness 
and negative self-evaluation that can ultimately be associated with eating disorders. Thus, possible selves uniquely capture the self-directed nature of development and bring into focus the role of these individualized future-oriented representations in regulating behaviors.

\section{Discrepancies within the working self concept}

Activation of emotional states within the self. From an affective perspective, the activation of possible selves into the working self-concept triggers strong emotional states that will impact upon one's motivation to take action towards a desired outcome. For instance, Atkinson (1957) suggested that the activation of predominant negative possible selves could lead to inaction and behavioral inhibition. Indeed, while positive feelings associated with a positive self will prompt more positive outcomes, the overwhelming anxiety attached to a feared possible self is likely to impede one's performance by influencing the content and form of subsequent behaviors (Markus \& Nurius, 1986; Markus \& Ruvolo, 1989).

Moreover, affects can emerge within the self-concept as a result from a discrepancy between the actual self and the possible selves activated at a given time (Markus \& Nurius, 1986). Researchers have demonstrated that the ability to achieve specific self-conceptions determines how individuals feel about themselves. In the selfdiscrepancy theory, Higgins (1987) suggested that individuals experiencing conflicting self-conceptions would be prone to emotional vulnerability. Ultimately, the discrepancy between the actual self and self-guides (i.e., the ideal self or ought self) triggers negative emotional-motivational states. Discrepancies between actual and ideal selves have proved 
predictive of dissatisfaction with self (Higgins, Klein, \& Strauman, 1985) and it was suggested that self-discrepancies might become even more influential in the course of adulthood (Rosenberg, 1979). Those negative emotional states can in turn be responsible for patterns of self-defeating behaviors (Strauman, 1989). Strauman, Vookles, Berenstein, Chaiken and Higgins (1991) observed that discrepancies between the actual and ought self were predictive of disordered eating. These authors suggested that the inability to reduce the discrepancy created enduring negative self-evaluation that, in turn, led to disordered eating. Moreover, as affects emerging within the working self-concept change from one time to another, one's sense of worth as an individual fluctuates accordingly. Rather than being a stable evaluation of one's worth, self-esteem fluctuates based on the valence of the self-schemas activated at a given times (Markus \& Nurius, 1986).

Discrepancies and self-esteem. From that perspective, self-esteem can be best understood as being shaped by conceptions about the self. It has been demonstrated that each of the self-components (i.e., past self, now self, possible self, and probable self) significantly contributes to self-esteem (Markus \& Nurius, 1986). The latter further highlights possible selves as an independent dimension that provided a unique contribution to one's motivational and affective state. Furthermore, the self-discrepancy was shown to account for a significant part of the variance in self-esteem measures (Pelham \& Swann, 1989). Moreover, Knox, Funk, Elliott, and Greene Bush (1998) found that girls' feared physical-appearance possible selves (i.e., "being fat", "being obese") were related to measures of their self-esteem, thus highlighting the significance of 
appearance-related concerns in self-evaluation in adolescent girls. Overall, these results showed that self-esteem is tied to the way every individual frames his or her self-views. One's sense of self-worth will therefore be colored by the meaning attributed to his or her self-conceptions and the context in which they emerge. Whether a woman is satisfied or not with her body weight and shape might extend to the way she evaluates herself overall and therefore will impact her overall self-esteem (McFarlane, McCabe, Jarry, Olmsted, \& Polivy, 2001; Morris, Goldsmith, Roll, \& Smith, 2001).

If conflicts or shifts within the self-concept can influence affective states, one's evaluation of her self-worth can in turn lead to detrimental behaviors. Indeed, self-esteem has been shown to be associated with dieting (Ackard, Croll, \& Kerney-Cooke, 2002) and disordered eating (Moor, Vartanian, Touyz, \& Beumont, 2004), thus becoming a risk factor for such pathologies (Button, Sonuga-Barke, Davies, \& Thompson, 1996; Ghaderi, 2003; Polivy \& Herman, 2002; Stice, Presnell, \& Spangler, 2002). Altogether, research suggests that behaviors are significantly impacted by self-schemas, and that this relationship is best understood in light of the affects attached to the activation of specific self-conceptions.

\section{Disordered eating and the self concept}

In the last decades, body image has emerged as a salient concept in the study of disordered eating and further became a precursor to the interest in the influence of selfschemas on eating habits. Body image is a multidimensional construct that encompasses both self-perceptions and attitudes about one's physical appearance. Recently, the highly prevalent "normative discontent" and body dissatisfaction that is commonly found among 
college-aged women has leveled-off and may be decreasing somewhat (Cash, Morrow, Hrabosky, \& Perry, 2004; Rodin, Silberstein \& Striegel-Moore, as cited in Polivy \& Herman, 2007). This decrease may not reflect a change towards a more accepting attitude about weight, but rather a greater cultural integration or normalization of the beliefs and behaviors associated with disordered eating. Mounting evidence indicates that body image dissatisfaction is paramount in the etiology of emotional distress and disordered eating (Berg, Frazier, \& Sherr, 2009; Perez \& Joiner, 2003; Stice, 1994, 2002).

When exploring concerns with body weight and physical appearance, gender asymmetry is consistently apparent: women are much more unhappy with their body than men are (Fallon \& Rozin, 1985; Miller et al., 2000; Mintz \& Kashubeck, 1999). There is also ethnic and racial diversity in the extent of body dissatisfaction. There are also ethnic and racial differences in the extent of body dissatisfaction. For example, body dissatisfaction is even more prevalent in European American women as opposed to Africa American women. This inequity may be attributed to the finding that African American woman are less-likely to internalize culturally condoned beauty standards and to compare themselves to media figures than European American women (Botta, 2000; Jefferson \& Stake, 2009). Hispanic women are not less affected by body dissatisfaction than European-American (Grabe \& Hyde, 2006) and they might even be at greater risk for adopting eating disorders behaviors than previously acknowledged (Robinson, et al., 1996). Nevertheless, regardless of their actual weight and their cultural/ethnic background, most women tend to be dissatisfied with their body image, and describe 
themselves as heavier than they actually are (DiGioacchino, Sargent, \& Topping, 2001; Grigg, Bowman, \& Redman, 1996).

Internalization of cultural standards. As mentioned above, self-perceptions of one's body have been associated with disordered eating. These constructs have been consistently described as an artifact of the cultural environment in which women are embedded. In Western countries, since the middle of the $20^{\text {th }}$ century there has been a transition from curviness, as famously embodied by Marilyn Monroe, towards greater thinness as a cultural standard for attractiveness in women. This transition has been influenced by mainstream media that have focused greater attention on thinner figures, thus exposing adolescent girls and women to images, that when internalized, often leads to establishing unattainable goals. Repeated exposure to images reflecting an excessive thinness is not harmless (Harrisson \& Cantor, 1997), and it has been unveiled as a factor creating negative feelings in women about their own bodies (Groesz, Levine, \& Murnen, 2002; Grabe, Ward, \& Hyde, 2008). Although the media influence is not reflected in every individual, internalization of cultural standards of attractiveness appears to mediate the link between external messages on thinness and figure dissatisfaction (Cafri, Yamamiya, Brannick, \& Thompson, 2005; Keery, van den Berg, \& Thompson, 2004; Stice, Schupak-Neuberg, Shaw, \& Stein, 1994; Tiggemann, 2003).

Adolescent girls and women invest in their bodies as a strategy to compensate for distressful identity disturbances (Vartanian, 2009). For example, Stein and Corte (2003, 2007) suggested that concerns about weight and shape stemmed from a failure to generate multiple areas of self-definition. To highlight the brevity of the problem, Bulik 
and Kendler (2000, p. 1757) report the case of a patient who claimed that "a life without an eating disorder would be a life without an identity." Taken together, this case and a good deal of prior research indicate that individuals who have failed to develop a sense of identity may be more vulnerable to internalization of cultural standards of appearance and beauty. Engaging in diet behaviors, considered acceptable and appropriate within the peer group and culture, may be considered an adaptive response for individuals who are struggling with an unstable sense of self. Body weight and shape perception influenced heavily by internalized cultural ideals have further been acknowledged as main motivational characteristics for women who are dieting or demonstrate disordered eating. These constructs can serve as an evaluative standard against which their self-worth is assessed (Polivy \& Herman, 2007).

From body image to physical self concept. Examining the shift from body image, as a pictorial self-conception, to a semantic-based self-conception has enabled researchers to further explore the parameters of self-concept in women with eating disorders. In an earlier study using the self-schema model as the conceptual framework, Stein \& Hedger (1997) observed that girls with a fat and out-of-shape self-schema had a lower self-esteem, significantly higher levels of emotional distress, and they reported more dieting habits - previously described as a proximal cause of disordered eating. Thus, the physical-appearance that was internalized in the form of a self-schema might have served as a guide for eating-related behaviors. More recently, research demonstrated that women with clinical eating disorders had less positive and more negative selfschemas than the control group (Stein \& Corte, 2007). In addition, results showed that 
women with Bulimia Nervosa carried a fat self-schema constantly available in memory, which seems to be a proximal motivator for eating disorders. However, the results did not suggest the availability of a fat self-schema in women with Anorexia Nervosa. If the perceptions of themselves in the here-and-now did not convey a sense of themselves as overweight, could it be their possible selves that prompted them to endorse unhealthy eating behaviors? It might "be a fear of being unattractive to others or overweight" that influences the most adolescent girls and women self-view as suggested by Knox (2006, p. 66). Moreover, as highlighted in the DSM-IV-TR (American Psychiatric Association, 2000), individuals diagnosed with Anorexia Nervosa "intensely fear gaining weight or becoming fat" regardless of their actual weight and that fear is observed as well in a majority of women struggling with subclinical symptoms of disordered eating. The apprehension of becoming overweight is strongly vivid in the experience of disordered eating and yet, the cognitive representations of the possible selves associated to this experience has received little to no attention.

Taken together, the literature to date demonstrates a clear pattern in which selfconcept consistently predicts disordered eating behaviors. Evidence is amassing that there are linkages among various constructs of the self-system and cognitive and behavioral aspects of body image and disordered eating. Yet, so far, research on disordered eating has focused mainly on one's perceptions of his or her physical self-concept in the hereand-now. Despite the evidence that future-oriented representations of the self (i.e., possible selves) are strong motivators of behaviors (Cross \& Markus, 1991), investigation of the influence of possible selves on disordered eating remained extremely scarce. 


\section{Research questions}

The present study will contribute to the knowledge on self-concept as it relates to disordered eating and further extend it by offering some insight into the association between possible selves of college women and their eating habits. This study will address the dearth of knowledge on eating disorders and possible selves and suggest some new direction for future research in that domain. Beyond a theoretical interest, the contribution of this study might yield significant implications for clinical practice and therapeutic treatment. Indeed, by helping to generate and/or recruit new possible selves into their working self-concept women's negative self-evaluation and associated disordered eating might be alleviated. This latter direction for future clinical work is further supported by research highlighting that the generation of possible selves might be a mechanism drawn upon in the identity exploration process (Dunkel \& Anthis, 2001). Encouraging the development of a new array of possible selves might facilitate the adoption of healthier eating habits and a more positive sense of self in women, ultimately helping them exist outside of the symptoms of disordered eating. Since possible selves are not tied to social feedback and behavioral evidence, they might be responsive to change (Markus \& Nurius, 1986).

Because disordered eating is prevalent in women in early adulthood, it is likely that they will have created appearance-related possible selves. Indeed, research has shown that young women report possible selves in the physical domain (Knox, Funk, Elliott, \& Green Bush, 1998). Therefore, this study will explore disordered eating by looking at college women's appearance-related possible selves. First, we will explore the 
repertoire of appearance-related possible selves of college women exhibiting disordered eating. More specifically, balance within the domain of appearance-related possible selves will be explored. That is, the presence of both a hoped-for appearance-related self with a countervailing feared appearance-related self. We will also explore the impact of appearance-related possible selves on disordered eating. Finally, we will explore how self-esteem may mediate or moderate the relationship between appearance-related possible selves and disordered eating. Ultimately, we ask the following questions: Do college women with disordered eating exhibit a specific pattern of possible selves? How do possible selves influence disordered eating? How does self-esteem influence the relationship between possible selves and disordered eating?

In this study, we will test several hypotheses: (1) College women with appearance-related possible selves will report more disordered eating than women who do not carry appearance-related possible selves. It is also expected that the configuration of women's possible selves can distinguish between their eating habits; specifically, women who display the least balance between their hoped-for and feared possible selves will report more disordered eating behaviors. (2) The second hypothesis is that there will be significant relationships among appearance-related possible selves, current selfschemas (as measured by the PSDQ) and disordered eating; (3) Finally, consistent with previous findings (Strauman, Vookles, Berenstein, \& Higgins, 1991), we expect selfesteem to play a role in the relationship between appearance-related possible selves and disordered eating. 


\section{CHAPTER III}

\section{METHODOLOGY}

Participants

A total of 293 female college students participated in this study. Ages ranged from 17 to 54 . The mean age was $22(S D=5)$. The majority of participants were Hispanic $(n=200,70.4 \%)$, followed by African American $(n=36,12.7 \%)$, White Caucasian $(n=26$, 9.2\%), and Asian ( $\mathrm{n}=11,3.9 \%)$. For participants who considered themselves "other" $(n=11,3.9 \%)$, the ethnicities included Jamaican, Haitian, Bahamian, and Indian.

The majority of participants reported never being married $(n=258,88.7 \%)$, followed by married $(n=17,5.8 \%)$, divorced $(n=12,4.1 \%)$, separated $(n=3,1.0 \%)$, and widowed $(n=1,0.3 \%)$. For education, most participants reported themselves at the partial college level $(n=144,49.7 \%)$, followed by high school graduate $(n=103,35.5 \%)$, college graduate $(n=36,12.4 \%)$, graduate or professional degree $(n=5,1.7 \%)$, and grade school $(n=2,0.7 \%)$.

More than half of the participants considered themselves in good health $(n=168$, $57.9 \%)$. The others were as follow: 58 rated their health as "excellent" (20\%), 55 rated it as "fair" (19\%), and 9 rated it as "poor" (3.1\%). Most of the participants reported that they were not currently on a diet $(n=212,72.9 \%)$ while 79 participants $(27.1 \%)$ reported they were. Participants reported that they engaged in physical exercise on average 4.3 hours every week $(S D=3.53)$. 
The mean Body Mass Index (BMI) for the sample was $24.1(S D=5.22)$. The BMI ranged from 15.53 and 50.17. The mean in pounds of the measured weight of participants was $139.79(S D=34.61)$ and the mean of the self-reported weight was $138.87(S D=32.59)$. Demographic information is presented in Table 1.

\section{Procedure}

Participants were recruited through the Florida International University Department of Psychology Research Participation System. Through Sona Systems Ltd. participants reserved a time and date at their convenience. Upon arriving in the Health \& Aging Laboratory for their interview session, the interviewer explained the procedure and participants were encouraged to ask any questions or express any concerns they might have. Participants then signed an informed consent (See Appendix A). The administration of the interview took approximately 30 minutes. It began with demographic information (See Appendix B), followed by the scales described below. Once the interview was completed, the principal interviewer debriefed the participants, addressed any questions they might have and thanked them for taking part in the study.

\section{Measures}

The Possible Selves Interview. In order to assess possible selves of college women we used a face-to-face interview designed for the purpose of this study (See Appendix C). This procedure was initially designed by Cross \& Markus (1991) and later modified by Hooker (1992). The investigator started by introducing the concept of possible selves to the participant, reading the following statement: 
This part of the questionnaire addresses how you see yourself in the future. We all think about our futures to some extent. When doing so, we usually think about the kind of experiences that are in store for us and the kinds of people we might possibly become. Sometimes we think about what we hope to become-selves we hope to become in the future, or "hoped for possible selves." Some hoped-for possible selves seem quite likely, like becoming a homeowner. Other future selves seem quite far-fetched but are still possible, for example, winning the lottery. Things that we do are not possible selves but are usually part of a possible self. Please take a few minutes and think about all your hoped-for possible selves. You may have just a few or you may have many.

The participants were asked to generate their own hoped-for possible selves. The investigator recorded the selves as they were verbalized. Then the possible selves were read to the participants who were asked to rank them in order of importance. The three most important were discussed further. For each of them, the participants were asked to provide a detailed description and explain why it is important to them. The participants were asked to discuss behaviors they engage in their daily life to ensure that the self would become a reality, as well as the obstacles they may encounter. They were also asked to explain how the self came into being.

A coding strategy derived from Frazier and Hooker's (2006) coding scheme was used for the qualitative data (See Appendix D). Possible selves were coded into one of 18 categories corresponding to salient domains of the self (i.e., personal, physical, lifestyle, occupation, material, success, and others). In order to establish inter-rater reliability, the data were coded independently by the Principal Investigator and by a trained research 
assistant who will be blind to the hypotheses. When discrepancies emerged discussion ensued until consensus was reached. Coded possible selves represent categorical data. At the data analytic level a dummy coded variable was constructed to allow for the analysis of presence/absence $($ coded present $=1$; absent $=0)$ of specified domains.

Following Hooker et al. (1996), a secondary coding scheme was used to provide detailed information on the different expressions of appearance-related possible selves (See Appendix E). Salient features of appearance - as outlined in the literature review were used to design the secondary coding schemes (weight, body image, dieting, exercise/activity, attractiveness/beauty, strength/muscularity, health problems/personal health, and other). This secondary coding scheme allows for a more conservative evaluation of the presence of appearance-related possible selves. The primary coding scheme allowed categorization of the self into domains expected to relate to body image and disordered eating on a general level (i.e., physical self, personal self, relationship self, success self). However, to further examine the specific details of the articulation of self-conceptions and disordered eating in possible selves and to examine the extent and depth to which these cognitive and behavioral antecedents of eating disorders are integrated into one's self-representations all the possible selves generated were coded using this secondary coding scheme. In order to establish inter-rater reliability, the data were coded independently by the Principal Investigator and by a trained research assistant who was blind to the hypotheses. When discrepancies emerged discussion ensued until consensus was reached. Secondary possible selves are also categorical data. At the data 
analytic level a dummy coded variable was constructed to allow for the analysis of presence/absence $($ coded present $=1$; absent $=0)$ of specified secondary domains .

Self-regulatory questions. Following the protocol, after three hoped-for possible selves have been generated, the participants answered a series of five questions that offer quantitative data on their self-regulatory processes. The questions address the distance of future self ("To what extent does this possible self describe you now?"), and ("To what extent would you like this possible self to describe you in the future?"), centrality ("How important is it for you to achieve this possible self?"), self-efficacy for achieving the self ("How capable do you feel of achieving this possible self") and their outcome expectancy for achieving the self ("How likely do you think it is that this possible self will be achieved?"). The participant answered every question on a seven-point Likert scale for each of the three hoped-for possible self they generated.

The possible selves protocol was then be repeated to generate feared possible selves. The phrasing was then modified to represent selves that are to be avoided. Following the generation of the feared possible selves each participant also answered the self-regulatory questions for each feared self.

In addition, balance among hoped-for and feared possible selves was assessed, following Frazier, Cotrell and Hooker (2003), and Oyserman and Markus (1990; 1993; 1998). For data analytic purposes a dummy coded variable was constructed to assess balance. Specifically a self will be coded for BALANCE (0) if the participant has generated both a hoped-for and a feared possible self coded within the same category. A self will be coded as FEAR-ONLY (-1) is only a feared self was present in the category, 
and the self will be coded as HOPE-ONLY $(+1)$ if only a hoped-for self was present within the same category. Balance was examined at both the primary and secondary coding levels.

To summarize, the data recorded from the possible selves interview consisted of: a) qualitative data coded into primary categorial data on the content of hoped-for and feared selves (coded 1-18); b) qualitative data of the content of the possible selves coded into a secondary coding scheme (coded $0-8)$; c) coding representing presence or absence of balance; e) quantitative data pertaining to the self-regulatory processes related to each possible self.

Physical Self-Description Questionnaire (PSDQ). The PSDQ (Marsh, Richards, Johnson, Roche, \& Tremayne, 1994) is a 70-item self-report that assess 10 facets of the physical self along with self-esteem. More specifically, the PSDQ contains 11 subscales, 9 of which explore perceptions of self that are related to specific areas of physical fitness and competence (Activity, Appearance, Body Fat, Coordination, Endurance, Flexibility, Health, Sport, Strength). One subscale is related to global physical competence and one subscale measures global self-esteem (See Appendix F). Each subscale contains 6 or 8 items. For each of the 70 statements, the participants must indicate the extent to which it applies to themselves, using a scale ranging from 1 (False) to 6 (True). Although the questionnaire was designed for use with adolescents, researchers (Marsh, 1997; Marsh et al., 1994) have postulated that the instrument should also be appropriate for use with adults; it has further been demonstrated appropriate for use in cross-cultural settings with adult subjects (Marsh, Asci, \& Tomas, 2002). For the 9 subscales related to specific areas 
of the physical self, scores range from 0 to 36 (for the 6-item subscales) and from 0 to 48 (for the 8-item categories). Each score reflects the individual's self-perception in regards to the specific domain of the physical self under scrutiny; with a higher score reflecting more positive self-representations. Specific subscales of the PSDQ were used to evaluate self-representations (i.e., self-schemas) related to particular domains of the physical self. Specifically, the Strength, Body Fat, Appearance, Health as well as the Physical-Activity subscales were used to derive information about participants' current representations pertaining to the physical self. Cronbach's Alphas for the 5 subscales that were used ranged from .83 to .93 .

Eating Attitudes Test (EAT-26). The EAT-26 (Garner \& Garfinkel, 1979; Garner, Olmsted, Bohr, \& Garfinkel, 1982) is a 26-item self-report questionnaire (See Appendix G). This widely used standardized questionnaire was used to measure symptoms and concerns characteristics of eating disorders - yet the EAT-26 alone does not diagnose eating disorders. A score can be determined for each of the 3 subscales: dieting (ranging from 0 to 39), bulimia/food preoccupation (ranging from 0 to 18) and oral control (ranging from 0 to 21). For all the subscales, higher scores indicate greater concerns pertaining to disordered eating. A total score -ranging between 0 and $78-$ is determined for each participant with scores at or above 20 indicating a high level of concern about dieting, body weight or problematic eating behaviors. An affirmative answer to one of the six behavioral questions suggests the need for an evaluation by a trained mental health professional. The Cronbach's Alpha coefficient for the EAT-26 was found to be .87 . 
Rosenberg Self-Esteem Scale (SES). A 10-item measure developed by Rosenberg (1965) was used to measure global self-esteem (See Appendix H). The 10 items are answered on a 4-point Likert scale; from strongly agree to strongly disagree. Five items require item-reversal, after item reversals scores are summed. The total score ranges between 0 and 30; and the higher the score, the higher the self-esteem. The SES has demonstrated good reliability and validity across a large number of different sample groups. The Cronbach's Alpha coefficient was found to be .80 .

Body Mass Index (BMI). The BMI was calculated from the participant's weight and height as measured by the investigator. When those measures were not available, self-reported height and weight were computed. The BMI provides a reliable indicator of body fatness for most people and is used to screen for weight categories that may lead to health problems.

Demographic data. Demographic information were collected for each participant, including age, race, education, marital status, history of eating disorders, dieting habits, practice of physical activity, weight, height and health status.

\section{Data analysis}

Data were analyzed using SPSS. A probability level of .05 served as the criterion for determining significance. Prior to the study, a power analysis was conducted, and it was determined that with a sample size of 300 college women, we would have sufficient statistical power to detect moderate effect sizes. 
As mentioned above, in this study, we tested several hypotheses:

(1) College women with appearance-related possible selves will report more disordered eating (as indicated by the total score on the EAT-26) than women who do not display appearance-related possible selves. It is also expected that the configuration of women's possible selves can distinguish between their eating habits; specifically, women who display the least balance between their hoped-for and feared possible selves will have a higher total score on the EAT-26.

(2) The second hypothesis is that there will be significant relationships among appearance-related possible selves, current self-schemas (as measured by the following subscales of the PSDQ: Strength, Body Fat, Appearance, Health and Physical Activity) and disordered eating. The third hypothesis tests the meditational or moderating influence of self-esteem in the relationships among possible selves and disordered eating. Self-esteem as a mediator or moderator was explored. 


\section{CHAPTER IV}

\section{RESULTS}

\section{Demographic and descriptive data}

Participants. A total of 293 female college students participated in this study. The mean age was $22(S D=5)$. Ages ranged from 17 to 54 . All participants were enrolled in Psychology classes at Florida International University and received a course credit for participating in the study. The mean Body Mass Index (BMI) for the sample was 24.1 $(S D=5.22)$. On the basis of their BMI, $7 \%$ of the participants were considered underweight $(\mathrm{BMI}<18.5), 63 \%$ had a normal weight $(18.5<\mathrm{BMI}<24.9), 18 \%$ were overweight $(25<\mathrm{BMI}<29.9)$, and $12 \%$ were obese $(\mathrm{BMI}>30)$. The mean score on the EAT-26 was $12.38(S D=10.83)$, and the scores ranged from 0 to 48 . Within our sample, $20 \%$ of participants reported a score indicative of a higher risk for eating disorders (EAT26 total score $>20)$.

Possible selves. The most common hoped-for selves for the sample were in the domains of family (24.5\%), occupation (21\%), and education (19\%). The most common feared possible selves were in the domains of personal characteristics $(22.5 \%)$, family $(14.3 \%)$, and success $(9.5 \%)$. A total of 154 participants or $53 \%$ of the sample reported at least one appearance-related possible self. Within the sample, hoped-for appearance selves accounted for $9.7 \%$ of the total possible selves while feared appearance selves accounted for $17.2 \%$. For students who reported an appearance-related possible self, the most common hoped-for selves were in the domains of health $(29 \%)$, body image $(27 \%)$, 
and weight $(26 \%)$. The most common feared selves within the secondary coding scheme were in the domains of weight (43\%) and health (47\%).

\section{Possible selves and disordered eating}

Hypothesis one examined the relationships between possible selves and disordered eating on two different levels. First, it was hypothesized that college women with appearance-related possible selves would report more disordered eating. Second, it was hypothesized that disordered eating would be associated with less balance in possible selves.

First, to determine the level of disordered eating (as indicated by the Total score on the EAT-26) for participants with and without an appearance-related possible self, an independent groups t-test was performed. There was a significant difference in disordered eating prevalence for female college students who reported an appearance-related possible self $(M=13.85, S D=11.09)$ and those who did not report an appearance-related possible self $(M=10.12, S D=9.60) ; t(288)=-3.04, p<.005$. This result indicates that, on average, female college students who reported an appearance-related possible self displayed more disordered eating compared to those who did not report an appearancerelated possible self.

In the second part of hypothesis one, we expected that women who displayed the least balance between their hoped-for and feared possible selves would display more disordered eating (as reported by the total score on the EAT-26). That second hypothesis could not be explored however due to the limited data available on balance of 
appearance-related possible selves. Indeed, in our sample, not enough students reported both a hoped-for and feared appearance possible-self within the same domain.

\section{Self-schemas and disordered eating}

The second hypothesis explored the potential relationships between appearancerelated possible selves, current self-schemas (as measured by the following subscales of the PSDQ: Strength, Body Fat, Appearance, Health, and Physical Activity), and disordered eating. First, it was anticipated that participants would differ in their selfschemas based on whether or not they reported an appearance-related possible self. More positive current self-representations were expected to be observed for participants who did not report an appearance-related possible self.

A between-subject multivariate analysis of variance (MANOVA) compared the means of the current self-schemas for participants with and without an appearance-related possible self. Five dependent variables were used: Strength, Body Fat, Appearance, Health, and Physical Activity. The independent variable was the presence and absence of an appearance-related possible self. Preliminary assumption testing was conducted to check for covariance matrices, linearity, univariate and multivariate outliers, homogeneity of variance-covariance matrices, and multicollinearity, with no serious violations noted. There was not a statistically significant difference between the participants with an appearance-related possible self and those without an appearancerelated possible self on the combined dependent variables: $F(5,290)=2.17, p=0.58$; Wilks' Lambda $=.96$; partial eta squared $=.04$. When the results for the dependent variables were considered separately, the only difference to reach statistical significance, 
using a Bonferroni adjusted alpha level of $p=.003$, was Body Fat, $F(1,290)=8.79, p=.003$, partial eta squared $=.03$. An inspection of the mean scores showed that female college students without an appearance-related possible self reported slightly more positive selfschemas $(M=26.80, S D=8.30)$ on the Body Fat subscale than students with an appearance-related possible self $(M=23.84, S D=8.70)$. These results indicate that not having an appearance-related possible self is related to more positive current weightrelated self-schemas than having an appearance-related possible self.

The second part of hypothesis two assessed the relationship between appearancerelated possible selves, current self-schemas (as measured by the subscales on the PSDQ) and disordered eating. It was anticipated that there would be significant relationships between appearance-related possible selves and disordered eating on one hand, and current self-schemas and disordered eating on the other hand. First, since appearancerelated possible selves is a categorical variable, Spearman rank order correlations were performed. The relationship between appearance-related possible selves (as reported by participants on the Possible Selves Interview) and disordered eating (as measured by the EAT-26) was investigated using Pearson product-moment correlation coefficient. Preliminary analyses were performed to ensure no violation of the assumptions of normality, linearity, and homoscedasticity. There was a positive correlation between the two variables, $r_{s}=.18, n=290, p=.002$. These results indicate that reporting an appearancerelated possible self is associated with higher disordered eating.

Pearson correlations were computed to assess the association between current self-schemas (as measured by 5 of the subscales of the PSDQ: Strength, Appearance, 
Body Fat, Health, and Physical Activity) and disordered eating (as measured by the EAT26). Preliminary analyses were performed to ensure no violation of the assumptions of normality, linearity, and homoscedasticity. There was a negative correlation between weight-related self-schemas (as measured by the Body Fat subscale of the PSDQ) and disordered eating, $r=-.36, n=291, p<.001$, with more positive self-schemas associated with lower disordered eating. There was also a negative correlation between appearancerelated self-schemas (as measured by the Appearance subscale of the PSDQ) and disordered eating, $r=-.24, n=291, p<.001$, with more positive appearance-related selfschemas associated with lower disordered eating. Finally, there was a positive correlation between activity-related self-schemas (as measured by the Physical Activity subscale of the PSDQ) and disordered eating, $r=.19, n=291, p=<.001$, with more positive activityrelated self-schemas associated with higher disordered eating.

The final part of hypothesis two was to assess the predictive influence of appearance-related possible selves and current self-schemas on disordered eating. It was expected that possible selves would be the major predictor of disordered eating and current self-schemas (as measured by 5 of the subscales of the PSDQ) claiming additional variance beyond the appearance-related possible selves. A hierarchical linear regression was used to assess the ability of those two variables to predict levels of disordered eating. Preliminary analyses were conducted to ensure no violation of the assumptions of normality, linearity, multicollinearity and homoscedasticity. The two variables were entered in a stepwise-fashion. In step 1, appearance-relation possible selves were entered, explaining $3.1 \%$ of the variance in disordered eating. In step 2 , the 
subscales of the PSDQ were entered, explaining an additional $18.4 \%$ of the variance in disordered eating, $R$ squared change $=.184, F$ change $(5,283)=13.24, p=<.001$. The total variance explained by the model as a whole was $21.5 \%, F(6,283)=12.90, p=<.001$. In the final model, only self-schemas were significant -with 2 of the subscales actually being statistically significant. The Body Fat subscale recorded a higher beta value (beta=-.30, $p=<.001$ ) than the Physical Activity subscale (beta $=.24, p=<.001)$. In sum, the data suggest that there is a direct effect of current self-schemas on disordered eating. Results are presented in Table 2.

Possible selves, self-esteem, and disordered eating

The third hypothesis examined the influence of self-esteem in the relationship between appearance-related possible selves and disordered eating. It was anticipated that self-esteem would serve as a moderator or mediator in that relationship.

First, self-esteem as a potential mediator was explored by performing a series of multiple regressions following Holmbeck (2006). The first two tests were intended to confirm a statistically significant linear relationship among the variables (appearancerelated possible selves; self-esteem; disordered eating). The third test was intended to establish the relative predictive weight of each predictor and determine whether or not self-esteem mediates the linkages among appearance-related possible selves and disordered eating. Results did not indicate self-esteem as a mediator between appearancerelated possible selves and disordered eating. 
Second, self-esteem as a moderator was explored by performing a series of multiple regression analyses following Holmbeck (2006). Appearance-related possible selves and self-esteem were entered in a step-wise fashion, followed by the interaction of the two variables. Disordered eating was the dependent variable. The results suggest that self-esteem does not serve as a moderator in the relationship between appearance-related possible selves and disordered eating. Results are presented in Table 3. 


\section{CHAPTER V}

\section{DISCUSSION}

The purpose of this study was to explore the relationship between appearancerelated possible selves and disordered eating in female college students. The preliminary assumption for this research was that self-concepts are associated with eating behaviors. More specifically, it was expected that, not only current self-schemas, but also futureoriented self-representations would be connected to dysfunctional eating behaviors. This hypothesis was supported by the data to some extent. Indeed, the integration of concerns for appearance and weight into the repertoire of possible selves was found to be associated with higher disordered eating. Furthermore, the present study reiterates that different constructs within the self-concept are proximal motivators for eating behaviors.

\section{Possible selves and disordered eating}

The first goal of this study was to establish the relationship between futureoriented self-representations and disordered eating. The literature abounds with demonstrations of the relationship between current self-schemas and disordered eating, but the influence of future-oriented self-representations has yet to be explored. Our study expanded on earlier work by highlighting results supporting the existence of a significant association between disordered eating and possible selves. Indeed, our result highlighted that levels of disordered eating are higher for students who reported an appearancerelated possible self. 
Balance within self-domains is paramount to achieving better behavior effectiveness (Frazier \& Hooker, 2006). We therefore expected that students who displayed unbalanced possible selves within the domain of appearance would be more prone to engage in dysfunctional behaviors, as measured by the level of disordered eating. The limited availability of data on balance of possible selves for the secondary coding scheme (appearance-related self-domains) did not allow us to explore the relationship between balance of selves and disordered eating. Our study however highlighted that, overall, students reported more feared possible selves than hoped-for possible selves within the domain of appearance.

\section{Influence of the self-concept on disordered eating}

The second goal of the study was to uncover the relationship between different constructs of the self-concept and disordered eating, and examine their predictive influence. Our findings indicate that students with an appearance-related possible self reported slightly less positive self-schemas. More specifically, the availability of an appearance-reated possible self was associated with more negative self-schemas for the Body Fat and Appearance subscales. These results suggest the continuity of appearancerelated concerns in one's self-concept, between current and future-oriented representations, and warrants that researchers explore the self-system as a dynamic entity. To that regard, Knox (2006) has previously suggested that women's fears of not being attractive or overweight might be the main precursor to their current self-schemas.

In addition, both appearance-related possible selves and self-schemas, and again, more specifically the Body Fat and Appearance subscales, were found to be linked to 
disordered eating. The influence of self-schemas on disordered eating appears however to be circumscribed to weight and appearance-related domains, and not to other aspects of the physical self (Health, Strength). Those results parallel prior observations by Stein \& Corte (2007) of the negative correlation between specific self-schemas (i.e., being fat and out-of-shape) and eating disorders. The present study further expands on previous findings by proposing the importance of possible selves in the study of dysfunctional eating behaviors.

If current self-schemas have been established as proximal behaviors for eating disorders, the influence of possible selves still has to be demonstrated. The existence of appearance-related possible selves might serve an instrumental role in motivating those dysfunctional eating behaviors. In the past, Cross \& Markus (1991) have indeed stressed the motivational role of possible selves in shaping future behaviors. Our data did not support the assumption that appearance-related possible selves served as the main predictor of disordered eating, with self-schemas claiming additional variance. Indeed, our results unveiled a model in which self-schemas, and specifically schemas related to body weight and physical activity, were accounting for a significant part of the variance of disordered eating. This model is in line with previous results that found that selfschemas were indirectly predicting clinical and subclinical eating disorders through the availability of a fat self-schema (Stein \& Corte, 2007; Stein \& Corte, 2008). Our study stressed upon the importance of looking at identity development in an attempt to shed light on eating disorders. 


\section{Influence of self-esteem on disordered eating}

The last goal of this research was to explore the effect of self-esteem in the relationship between possible selves and disordered eating. Self-esteem predicted disordered eating as demonstrated before (Moor, Vartanian, Touyz, \& Beumont, 2004). However, our results did not support self-esteem either as a mediator or as a moderator of the relationships between possible selves and eating behaviors. Previous studies have suggested that the difference between disordered eating and clinical eating disorders might not only be quantitative, but also qualitative. Affective symptomatology for instance has been identified as a variable that might differentiate between subclinical and clinical dysfunctional eating behaviors (Stice \& Agras, 1999). Seemingly, self-esteem might possibly serve as a moderator or mediator of eating disorders only for more severe eating disorders.

\section{Limitations}

This study has several potential limitations that ought to be addressed. First, the generalizability of the results is limited. The BMI scores of the students in the present study were comparable to those reported in previous studies in a representative sample of college students (Lowry, Galuska, Fulton, Weschler, Kann, \& Collins, 2000), however the ethnic makeup of the sample is specific to South Florida and is therefore not representative of American college students. Hispanic population accounted for more than half of the sample, with White non-Hispanic, African American, and Asian American being only minimally represented. In addition, the ethnic distribution within the Hispanic sample is unique to South Florida and reflects the Cuban-American heritage 
of the city of Miami. In a previous study, the frequent consumption of Cuban meals and primary use of Spanish in the household were associated with lower scores on the EAT26 in a sample of Cuban-American women (Dulce, Hunter, \& Lozzi, 1999). On the other hand however, previous studies suggested a higher prevalence of subclinical disordered eating behaviors and body dissatisfaction than previously reported in different samples of Hispanic women (Croll, Neumark-Sztainer, Story, \& Ireland, 2002; Robinson, et al., 1996). These results suggest that disordered eating behaviors might differ across ethnicities within the Hispanic population. We can therefore hypothesize that different patterns of disordered eating might have been reflected in a more representative sample.

Secondly, the high prevalence of academic and occupational possible selves reported by the students has to be considered in the specific context of the study. Indeed, the fact that students were to receive a course credit for participating in the study might have caused a social desirability bias to some extent. Seemingly, expressing concerns of "being fat or overweight" in a face-to-face interview might have been construed as negatively connoted to some degree. A written self-report of possible selves might have elicited different possible selves from the students. Another important limitation is that disordered eating was a self-report measure and may therefore reflect some biases, especially due to the fact that dieting behaviors have been internalized and normalized in our society and might not be perceived as inherently dysfunctional. In addition, our decision to work with a non-clinical population might shed some light on the fact that some of the models we were expecting to observe were not supported. In fact, appearance-related possible selves were not reported predominantly in our sample, which 
in turn might have not allowed us to observe the hypothesized relationships. In addition, the majority of the self-reported scores of disordered eating were low in our sample. In a clinical sample, we can suppose that the higher frequency of appearance-related possible selves generated by women might have enabled us to capture the influence of possible selves more distinctly.

Potential implications of the study

Fears and ideals about appearance in general, and weight particularly, have increased in our society in the last decades, to the point of becoming normative concerns. Our study highlights that those fears and hopes have been integrated into the self-concept, permeating not only our current self-representations, but also the future-oriented conceptions of our selves. Therefore, this study offers therefore a significant contribution to the literature on body image by introducing possible selves as a meaningful construct that can advance our understanding of the interplay between self-concept and appearance-related concerns. Moreover, women's account of future-oriented selfrepresentations reflect that they hold more fears than hopes within the domain of appearance, with an emphasis on health and weight-related concerns. This result stresses the importance of further examining appearance-related feared selves as it relates to the development of women's self-identity.

Our study also sheds some light on the relationship between possible selves and disordered eating in a non-clinical population. It reiterates the centrality of self-concept to the understanding of disordered eating and introduces the idea that possible selves might offer an unexplored, yet meaningful, avenue to this field of research. As a discipline, we 
need to shift our focus to a more dynamic conception of the self-concept, by accounting for appearance-related possible selves as significant correlates of dysfunctional eating behaviors. To that regard, the present study offers important directions for future research. In order to uncover the direct and indirect influence of possible selves on eating behaviors, it would be important to replicate the study in a clinical population of women with eating disorders. In addition, replicating the study across different diagnosis (anorexia nervosa and bulimia nervosa) might allow us to observe sensitive nuances in the effects of possible selves. For instance, it would be interesting to further explore how the fear of becoming overweight observed in women with anorexia nervosa is reflected in their possible selves.

The relationship we observed between appearance-related possible selves and disordered eating highlights the need to integrate future-oriented representations about the self in the prevention of disordered eating in women. Indeed, current self-schemas ("I am too fat", "I need to exercise") mentioned by women might only represent one layer of the foundation on which disordered eating develop, with possible selves potentially contributing to those behaviors as well. Possible selves are private in nature and can easily be left unnoticed and unvoiced; but educators and health care professionals need to address future hopes and weight-related fears that might be motivating unhealthy behaviors in women. Our study suggests that it might be useful to focus more specifically on feared possible selves within the domain of weight and health. Future studies will help clarify the interaction between possible selves and disordered eating and inform the development of targeted prevention campaigns and treatment interventions. 
Table 1

Descriptive Data for Demographic Information

\begin{tabular}{|c|c|c|c|}
\hline Variable & Total Sample & Appearance & Non Appearance \\
\hline \multicolumn{4}{|l|}{ Age } \\
\hline Mean (SD) & $22(5)$ & $21(4.5)$ & $22(5.4)$ \\
\hline \multicolumn{4}{|l|}{ Marital Status } \\
\hline Married & $17.5 \%$ & $7.1 \%$ & $4.4 \%$ \\
\hline Divorced & $4.1 \%$ & $5.2 \%$ & $2.9 \%$ \\
\hline Separated & $1.0 \%$ & $1.3 \%$ & $0.7 \%$ \\
\hline Widowed & $0.3 \%$ & $0 \%$ & $0.7 \%$ \\
\hline Never Married & $88.7 \%$ & $86.4 \%$ & $91.2 \%$ \\
\hline \multicolumn{4}{|l|}{ Education } \\
\hline Grade School & $0.7 \%$ & $0 \%$ & $1.5 \%$ \\
\hline High School & $35.5 \%$ & $35.3 \%$ & $36.0 \%$ \\
\hline Partial College & $49.7 \%$ & $49.7 \%$ & $49.3 \%$ \\
\hline College & $12.4 \%$ & $13.1 \%$ & $11.8 \%$ \\
\hline Graduate School & $1.7 \%$ & $2.0 \%$ & $1.5 \%$ \\
\hline \multicolumn{4}{|l|}{ Ethnicity } \\
\hline African American & $12.7 \%$ & $11.3 \%$ & $13.5 \%$ \\
\hline Asian & $3.9 \%$ & $2.0 \%$ & $6.0 \%$ \\
\hline Hispanic & $70.4 \%$ & $69.3 \%$ & $72.2 \%$ \\
\hline White Caucasian & $9.2 \%$ & $12.0 \%$ & $6.0 \%$ \\
\hline
\end{tabular}


Other

Health

Excellent

Good

Fair

Poor

Physical Activity

Mean (SD)

4.4(3.5)

4.3(3.2)

$4.4(3.8)$

ED Diagnosis

Yes

No

Medical Diagnosis

Yes

No

Current Diet

Yes

No

BMI

Mean (SD)
$22.3 \%$

$77.7 \%$

$27.1 \%$

$72.9 \%$

$64.9 \%$

$35.1 \%$

$18.4 \%$

$81.6 \%$

24.11(5.2)
$24.7 \%$

$75.3 \%$
$80.1 \%$

$2.9 \%$

$97.1 \%$

$19.9 \%$ 
Table 2

Hierarchical Linear Regression Analyses Predicting Disordered Eating From Appearance-Related Possible selves and Current Self-Schemas

\begin{tabular}{|c|c|c|c|c|}
\hline \multicolumn{5}{|c|}{$\mathrm{DV}=$ Disordered Eating } \\
\hline Variables & $\beta$ & $R^{2}$ & $R^{2}$ Change & $P$ \\
\hline Step 1 & & .031 & & $.003 *$ \\
\hline Appearance & .176 & & & \\
\hline \multicolumn{5}{|l|}{ group } \\
\hline Step 2 & & .215 & .184 & $.000 *$ \\
\hline Appearance & .114 & & & .034 \\
\hline \multicolumn{5}{|l|}{ group } \\
\hline Strength & -.019 & & & .773 \\
\hline Appearance & -.163 & & & .008 \\
\hline Body Fat & -.298 & & & $.000 *$ \\
\hline Health & -.050 & & & .346 \\
\hline Physical Activity & .236 & & & $.000 *$ \\
\hline
\end{tabular}

Note. *Significant at an alpha level of .05 
Table 3

Hierarchical Linear Regression Analyses Examining Self-Esteem as a Moderator

\begin{tabular}{|c|c|c|c|c|}
\hline \multicolumn{5}{|c|}{$\mathrm{DV}=$ Disordered Eating } \\
\hline Variables & $\beta$ & $R^{2}$ & $R^{2}$ Change & $P$ \\
\hline Step 1 & & .031 & & $.003 *$ \\
\hline Appearance & .176 & & & \\
\hline \multicolumn{5}{|l|}{ group } \\
\hline Step 2 & & .159 & .005 & $.000 *$ \\
\hline Appearance & .196 & & & $.000 *$ \\
\hline \multicolumn{5}{|l|}{ group } \\
\hline Self-Esteem & -.277 & & & $.000 *$ \\
\hline Appearance * & -.104 & & & .174 \\
\hline Self-Esteem & & & & \\
\hline
\end{tabular}

Note. * Significant at an alpha level of .05 


\section{REFERENCES}

Ackard, D. M., Croll, J. K., \& Kerney-Cooke, A. (2002). Dieting frequency among college females: Association with disordered eating, body image, and related psychological problems. Journal of Psychomatic Research , 52 (3), 129-136.

American Psychiatric Association. (2000). Diagnostic and Statistical Manual of Mental Disorders (4th ed., text rev. ed.). Washington, DC: Author.

Atkinson, J. W. (1957). Motivational determinants of risk-taking behaviors. Psychological Review , 64, 359-372.

Bandura, A. (1989). Regulation of cognitive processes through perceived self-efficacy. Developmental Psychology, 25, 729-778.

Berg, K. C., Frazier, P., \& Sherr, L. (2009). Change in eating disorders attitudes and behavior in college women: Prevalence and predictors. Eating Behaviors , 10, 137-142.

Botta, R. A. (2000). The mirror of television: a comparison of black and white adolescents' body image. Journal of Communication , 50 (3), 144-159.

Button, E. J., Sonuga-Barke, E. J., Davies, J., \& Thompson, M. (1996). A prospective study of self-esteem in the prediction of eating problems in adolescent schoolgirls: Questionnaire findings. British Journal of Clinical Psychology , 35, 193-203.

Cantor, N., \& Kihlstrom, J. F. (1987). Personality and social intelligence. Englewood Cliffs, NJ: Prentice Hall.

Cooley, E., \& Toray, T. (1996). Disordered eating in college freshman women: A prospective study. Journal of American College Health , 44 (5), 229-235.

Croll, J., Neumark-Sztainer, D., Story, M., \& Ireland, M. (2002). Prevalence and risk and protective factors related to disordered eating behaviors among adolescents: relationship to gender and ethnicity. Journal of Adolescent Health , 31 (2), 166175.

Cross, S., \& Markus, H. (1991). Possible selves across the life span. Human Development , 34, 230-255.

Dulce, J., Hunter, G., \& Lozzi, B. (1999). Do Cuban American women suffer from eating disorders? Effects of media exposure and acculturation. Hispanic Journal of Behavioral Sciences , 21 (2), 212-218. 
Dunkel, K. S., \& Anthis, K. S. (2001). The role of possible selves in identity formation: a short-term longitudinal study. Journal of Adolescence , 24, 765-776.

Fallon, A. E., \& Rozin, P. (1985). Sex differences in perceptions of desirable body shape. Journal of Abnormal Psychology, 94 (1), 102-105.

Franken, R. (1994). Human motivation, Third Edition. Pacific Grove, CA: Brooks/Cole.

Frazier, L. D., Cotrell, V., \& Hooker, K. (2003). Possible selves and illness: A comparison of individuals with Parkinson's disease, early-stage Alzheimer's disease, and healthy older adults. International Journal of Behavioral Development , 27 (1), 1-11.

Garner, D. M., Olmsted, M. P., Polivy, J., \& Garfinkel, P. E. (1984). Comparison between weight-preoccupied women and anorexia nervosa. Psychosomatic Medicine , 46 (3), 255-266.

Ghaderi, A. (2003). Structural modeling analysis of prospective risk factors for eating disorder. Eating Behaviors , 3, 387-396.

Grabe, S., \& Hyde, J. S. (2006). Ethnicity and body dissatisfaction among women in the United-States: A Meta-Analysis. Psychological Bulletin , 132 (4), 622-640.

Grabe, S., Ward, M. L., \& Hyde, J. S. (2008). The role of the media in body images concerns among women: A meta-analysis of experimental and correlational studies. Psychological Bulletin , 134 (3), 460-476.

Groesz, L. M., Levine, M. P., \& Murnen, S. K. (2002). The effect of experimental presentation of thin media images on body satisfaction: A meta-analytic review. International Journal of Eating Disorders , 31, 1-16.

Harrisson, K., \& Cantor, J. (1997). The relationship between media consumption and eating disorders. Journal of Communication , 47 (1), 40-67.

Higgins, E. T. (1987). Self-discrepancy: A theory relating self and affect. Psychological Review, 94, 319-340.

Higgins, E. T., Klein, R., \& Strauman, T. (1985). Self-concept discrepancy theory: A psychological model for distinguishing among different aspects of depression and anxiety. Social Cognition , 3, 51-76.

Hoek, H. W., \& Van Hoeken, D. (2003). Review of the prevalence and incidence of eating disorders. International Journal of Eating Disorders , 34 (4), 383-396.

Hooker, K., \& Kaus, C. R. (1992). Possible selves and health behaviors in later life. Journal of Aging and Health , 4, 390-411. 
Hudson, J. I., Hiripi, E., Pope, H. G., \& Kessler, R. C. (2007). The prevalence and correlates of eating disorders in the National Comorbidity Survey Replication. Biological Psychiatry, 61, 348-358.

Jacobi, C., Hayward, C., De Zwaan, M., Kraemer, H. C., \& Agras, S. W. (2004). Coming to terms with risk factors for eating disorders: Application of risk terminology and suggestions for a general taxonomy. Psychological Bulletin , 130 (1), 19-65.

Jefferson, D. L., \& Stake, J. E. (2009). Apperance self-attitudes of African American and European American women: Media comparisons and internalization of beauty ideals. Psychology of Women Quarterly, 33, 396-409.

Keel, P. K., Baxter, M. G., Heatherton, T. F., \& Joiner, T. E. (2007). A 20-year longitudinal study of body weight, dieting and eating disorder symptoms. Journal of Abnormal Psychology, 116 (2), 422-432.

Kendzierski, D. (1988). Self-schemata and exercise. Basic and Applied Social Psychology, 9, 45-59.

Knox, M., Funk, J., Elliott, R., \& Green Bush, E. (1998). Adolescents' possible selves and their relationship to global self-esteem. Sex Roles , 39 (1/2), 61-80.

Krahn, D. D., Kurth, C. L., Gomberg, E., \& Drewnowski, A. (2005). Pathological dieting and alcohol use in college women: a continuum of behaviors. Eating Behaviors , $6,43-52$.

Laessle, R. G., Tuschl, R. J., Waadt, S., \& Pirke, K. M. (1989). The specific psychopathology of bulimia nervosa: a comparison with restrained and unrestrained (normal) eaters. Journal of Consulting and Clinical Psychology , 57 (6), 772-775.

Lowry, R., Galuska, D., Fulton, J., Weschler, H., Kann, L., \& Collins, J. (2000). Physical activity, food choice, and weight management goals and practices among U.S. college students . American Journal Of Preventive Medicine , 18 (1), 18-27.

Markus, H. (1977). Self-schemas and processing information about the self. Journal of Personality and Social Psychology, 35, 63-78.

Markus, H., \& Herzog, A. R. (1992). The role of the self-concept in aging. In K. W. Schaie, \& M. P. Lawton, Annual Review of Gerontoly and Geriatrics (pp. 110143). New-York, NY: Springer.

Markus, H., \& Nurius, P. (1986). Possible selves. American Psychologist , 41 (9), 954969. 
Markus, H., \& Wurf, E. (1987). The dynamic self concept: A social psychological perspective. Annual Review of Psychology, 38, 299-337.

Markus, H., Hamill, R., \& Sentis, K. P. (1987). Thinking fat: Self-schemas for body weight and the processing of weight relevant information. Journal of Applied Social Psychology, 17 (1), 50-71.

Marsh, H. W., Asci, F. H., \& Tomas, I. (2002). Multitrait-multimethod analysis of two physical self-concept instruments: a cross-cultural perspective. Journal of Sport and Exercise Psychology , 24, 99-109.

Marsh, H. W., Richards, G. E., Johnson, E., Roche, L., \& Tremayne, P. (1994). Physical Self-Description Questionnaire: Psychometric properties and a multitraitmultimethod analysis of relations to existing instruments. Sport and Exercise Psychology, 16, 270-305.

McFarlane, T., McCabe, R., Jarry, J., Olmsted, M., \& Polivy, J. (2001). Weight-related and shape-related self-evaluation in eating-disordered and non eating-disordered women. Eating Behaviors , 29 (3), 328-335.

Miller, K. J., Gleaves, D. H., Hirsch, T. G., Green, B. A., Snow, A. C., \& Corbett, C. C. (2000). Comparisons of body image dimensions by race/ethnicity and gender in a university population. International Journal of Eating Disorders , 27 (310-316).

Mintz, L. B., \& Betz, N. E. (1998). Prevalence and correlates of eating disordered behaviors among undergraduate women. Journal of Counseling Psychology , 35 (4), 463-471.

Mintz, L. B., \& Kashubeck, S. (1999). Body image and disordered eating among Asian American and Caucasion college students: An examination of race and gender differences. Psychology of Women Quarterly, 23, 781-796.

Moor, S., Vartanian, L. R., Touyz, S. W., \& Beumont, P. J. (2004). The psychopathology of EDNOS patients: To whom do they compare? Clinical Psychologist , 8, 70-75.

Morris, M., Goldsmith, T., Roll, S., \& Smith, J. (2001). A model for assessing the selfschemas of restrained eaters. Cognitive Therapy and Research , 25, 201-214.

Pelham, B. W., \& Swann, J. W. (1989). From self-conceptions to self-worth: On the sources and structure of global self-esteem. Journal of Personality and Social Psychology , 57 (4), 672-680.

Polivy, J., \& Herman, C. P. (2002). Causes of eating disorders. Annual Review of Psychology , 53, 187-213. 
Reba-Harrelson, L., Von Holle, A., Hamer, R. M., Swann, R., Reyes, M. L., \& Bulik, C. M. (2009). Patterns and prevalence of disordered eating and weight control behaviors in women ages 25-45. Eating and Weight Disorders , 14 (4), 190-198.

Robinson, T., Killen, J., Litt, I., Hammer, L., Wilson, D., Haydel, F., Hayward, C., \& Taylor, C. B. (1996). Ethnicity and body dissatisfaction: Are Hispanic and Asian girls at increased risk for eating disorders? Journal of Adolescent Health, 19 (6), 384-393.

Rosenberg, M. (1979). Conceiving the self. New-York: Basic Books.

Rosenberg, M. (1965). Society and the adolescent self-image. Princeton, NJ: Princeton University Press.

Stein, K. F., \& Corte, C. (2007). Identity impairment and the eating disorders: Content and organization of the self-concept in women with anorexia nervosa and bulimia nervosa. European Eating Disorders Review , 15, 58-69.

Stein, K. F., \& Hedger, K. M. (1997). Body weight and shape self-cognition, emotional distress, and disodered eating in middle adolescent girls. Archives of Psychiatric Nursing , 11 (5), 264-275.

Stice, E., \& Agras, W. S. (1999). Subtyping bulimic women along dietary restraint and negative affect dimensions. Journal of Consulting and Clinical Psychology, 67 (4), 460-469.

Stice, E., Presnell, K., \& Spangler, D. (2002). Risk factors for binge eating onset: A prospective investigation. Health Psychology, 21, 131-138.

Strauman, T. J. (1989). The paradox of the self: A psychodynamic/social-cognitive integration. In R. C. Curtis, Self-defeating behaviors: Experimental findings, clinical impressions, and practical implications (pp. 311-339). New-York: Plenum Press.

Strauman, T. J., Vookles, J., Berenstein, V., Chaiken, S., \& Higgins, T. E. (1991). Selfdiscrepancies and vulnerabilities to body dissatisfaction and disordered eating. Journal of Personality and Social Psychology, 61 (6), 946-956.

Vartanian, L. R. (2009). When the body defines the self: Self-concept clarity, internalization, and body image. Journal of Social and Clinical Psychology , 28 (1), 94-126. 
APPENDICES 
Appendix A

\section{Informed Consent}

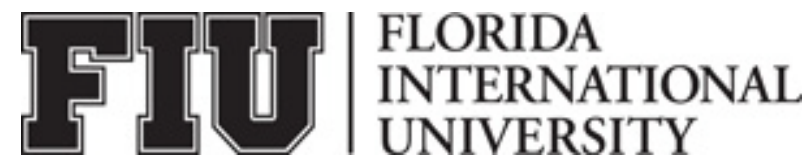

ADULT CONSENT TO PARTICIPATE IN A RESEARCH STUDY

THE INFLUENCE OF POSSIBLE SELVES ON EATING HABITS

\section{PURPOSE OF THE STUDY}

You are being asked to be in a research study. This study will be conducted by Aurelie Lucette as Principle Investigator under the direction of Dr. Leslie D. Frazier. The purpose of this study is to gain better understanding on how the representations of ourselves in the future might influence our eating habits.

\section{NUMBER OF STUDY PARTICIPANTS}

If you decide to be in this study, you will be one of 300 people in this research study.

\section{DURATION OF THE STUDY}

Your participation will require 30 minutes.

\section{PROCEDURES}

If you agree to be in the study, we will ask you to do the following things:

1. You will be asked a series of questions to answer about general demographic information, your eating behaviors, self-esteem and perceptions of yourself in the future.

2. All your answers will be written in an interview packet that does not identify you in any way. 


\section{RISKS AND/OR DISCOMFORTS}

There are no known risks involved in the participation in this study.

\section{BENEFITS}

The following benefits may be associated with your participation in this study: Your participation might help you gain insight into the way you see yourself and your current eating behaviors. It will also help researchers find out how to better help women who struggle with disordered eating.

\section{ALTERNATIVES}

There are no known alternatives available to you other than not taking part in this study. However, any significant new findings developed during the course of the research which may relate to your willingness to continue participation will be provided to you.

\section{CONFIDENTIALITY}

The records of this study will be kept private and will be protected to the fullest extent provided by law. In any sort of report we might publish, we will not include any information that will make it possible to identify a subject. Research records will be stored securely and only the researcher team will have access to the records. The U.S. Department of Health and Human Services (DHHS) and/or the Food and Drug Administration (FDA) may request to review and obtain copies of your records. Your records may also be reviewed for audit purposes by authorized University or other agents who will be bound by the same provisions of confidentiality. A code number will identify all questionnaires and your name will not appear on the interview packet.

\section{COMPENSATION \& COSTS}

You will receive 1 credit for your participation in that study. You will not be responsible for any costs to participate in this study.

\section{RIGHT TO DECLINE OR WITHDRAW}

Your participation in this study is voluntary. You are free to participate in the study or withdraw your consent at any time during the study. Your withdrawal or lack of participation will not affect any benefits to which you are otherwise entitled. The 
investigator reserves the right to remove you without your consent at such time that they feel it is in the best interest.

\section{RESEARCHER CONTACT INFORMATION}

If you have any questions about the purpose, procedures, or any other issues relating to this research study you may contact Aurelie Lucette at aurelie.lucette@gmail.com. If you want further information about that research you may also contact Dr. Leslie D. Frazier at 305/348-2045.

\section{IRB CONTACT INFORMATION}

If you would like to talk with someone about your rights of being a subject in this research study or about ethical issues with this research study you may contact Dr. Patricia Price, the Chairperson of the FIU Institutional Review Board (IRB) at 305-3482618 or $305-348-2494$.

\section{PARTICIPANT AGREEMENT}

I have read the information in this consent form and agree to participate in this study. I have had a chance to ask any questions I have about this study, and they have been answered for me. I understand that I am entitled to a copy of this form after it has been read and signed.

Signature of Participant

Date

Printed Name of Participant

Signature of Person Obtaining Consent

Date

Appendix B

Demographic Information 
Date:

1. How old are you?

2. What is your ethnic background?

$\square \quad$ African American

$\square \quad$ Asian

$\square \quad$ Hispanic

$\square \quad$ Native American

$\square$ White Caucasian

$\square \quad$ Other

3. What is your current marital status?

$\square \quad$ Married

$\square \quad$ Divorced

$\square \quad$ Separated

$\square \quad$ Widowed

$\square \quad$ Never Married

4. What is the highest grade you have completed?

$\square \quad$ Graduate/professional degree

$\square \quad$ College graduate

$\square \quad$ Partial college

$\square \quad$ High school graduate

$\square \quad$ Completed grade school 
5. Have you ever been diagnosed with an eating disorder?

$\square \quad$ Yes: How long ago?

$\square \quad$ No

6. Are you currently on a diet?

$\square \quad$ Yes

$\square \quad$ No

7. How many hours do you exercise every week?

8. Is your health:

$\square \quad$ Excellent

$\square \quad$ Good

$\square \quad$ Fair

$\square \quad$ Poor

9. Do you have any medically diagnosed or medically treated conditions?

$\square \quad$ Yes

$\square \quad$ No

If so, please list below any (all) diagnosed medical conditions and any associated treatments

10. What is your current weight?

11. What is your height?

Appendix C

POSSIBLE SELVES INTERVIEW PROTOCOL 
Interviewers introduce the concept of possible selves by reading the following to participants:

This part of the questionnaire addresses how you see yourself in the future. We all think about our futures to some extent. When doing so, we usually think about the kind of experiences that are in store for us and the kinds of people we might possibly become. Sometimes we think about what we hope to become-selves we hope to become in the future, or "hoped for possible selves". Some hoped-for possible selves seem quite likely, like becoming a homeowner. Other future selves seem quite far-fetched but are still possible, for example, winning the lottery. Things that we do are not possible selves but are usually part of a possible self. Please take a few minutes and think about all your hoped-for possible selves. You may have just a few or you may have many.

\section{Hoped-for Possible Selves}

Please take a few minutes and think about all of your HOPED-FOR POSSIBLE SELVES. You may have just a few, or you may have many. Identify as many as you can.

Then, please identify the 3 hoped-for possible selves that are currently the most important to you and order them in order of importance. You will use these chosen selves to respond to a series of questions that follow.

\section{HOPED-FOR POSSIBLE SELF \#1}

(Provide a detailed description of the self) 
1. Why is this hoped-for self important to you?

2. What kind of things have you done, or not done, recently to make this possible self happen in the future?

3. Are you experiencing any challenges or obstacles to achieving this self?

4. Now, thinking back to when you first decided that this hoped-for self was an important goal for the future: Can you identify an even, a personal realization, another person, or a particular influence that caused you to develop this possible self? (PLEASE DESCRIBE IN DETAIL):

5. To what extent does this possible self describe you now?

1

2
$4 \quad 5$

Somewhat
6

7

Not at all
3

6. To what extent would you like this possible self to describe you in the future?

$\begin{array}{lllllll}1 & 2 & 3 & 4 & 5 & 6 & 7\end{array}$

Not at all

Somewhat

Very much

7. How important is it to you to achieve this possible self in the future?
1
2
3
4
5
6
7

Not at all

Somewhat

Very much

8. How capable do you feel of achieving this possible self in the future?

$\begin{array}{llllllll}1 & 2 & 3 & 4 & 5 & 6 & 7\end{array}$

Not at all Somewhat Very much

9. How likely do you think it is that you WILL achieve this possible self in the future?
1
2
3
4
5
6
7 


\section{HOPED-FOR POSSIBLE SELF \#2}

(Provide a detailed description of the self)

1. Why is this hoped-for self important to you?

2. What kind of things have you done, or not done, recently to make this possible self happen in the future?

3. Are you experiencing any challenges or obstacles to achieving this self?

4. Now, thinking back to when you first decided that this hoped-for self was an important goal for the future: Can you identify an even, a personal realization, another person, or a particular influence that caused you to develop this possible self? (PLEASE DESCRIBE IN DETAIL):

5. To what extent does this possible self describe you now?

$\begin{array}{llllllll}1 & 2 & 3 & 4 & 5 & 6 & 7\end{array}$

Not at all

Somewhat

Very much

6. To what extent would you like this possible self to describe you in the future?

$\begin{array}{llllllll}1 & 2 & 3 & 4 & 5 & 6 & 7\end{array}$

Not at all

Somewhat

Very much

7. How important is it to you to achieve this possible self in the future?

$\begin{array}{llllllll}1 & 2 & 3 & 4 & 5 & 6 & 7\end{array}$

Not at all Somewhat Sery much

8. How capable do you feel of achieving this possible self in the future? 
9. How likely do you think it is that you WILL achieve this possible self in the future?
1
2
3
4
5
6
7

Not at all

Somewhat

Very much

\section{HOPED-FOR POSSIBLE SELF \#3}

(Provide a detailed description of the self)

1. Why is this hoped-for self important to you?

2. What kind of things have you done, or not done, recently to make this possible self happen in the future?

3. Are you experiencing any challenges or obstacles to achieving this self?

4. Now, thinking back to when you first decided that this hoped-for self was an important goal for the future: Can you identify an even, a personal realization, another person, or a particular influence that caused you to develop this possible self? (PLEASE DESCRIBE IN DETAIL):

5. To what extent does this possible self describe you now?

1

2

4

Somewhat
5

6

7

Not at all

Very much

6. To what extent would you like this possible self to describe you in the future?

$\begin{array}{llllllll}1 & 2 & 3 & 4 & 5 & 6 & 7\end{array}$

Not at all

Somewhat

Very much

7. How important is it to you to achieve this possible self in the future? 
1

2

3

4

Somewhat

Not at all

8. How capable do you feel of achieving this possible self in the future?

2

3

4

5

6

7

Not at all

Somewhat

Very much

9. How likely do you think it is that you WILL achieve this possible self in the future?

1

2

3

4

5

6

7

Not at all

Somewhat

Very much

\section{Feared Possible Selves}

Please take a few minutes and think about all of your FEARED POSSIBLE SELVES. You may have just a few or you may have many. Identify as many as you can. 
Then, please identify the 3 feared possible selves that are currently the most important to you and order them in order of importance. You will use these chosen selves to respond to a series of questions that follow.

\section{FEARED POSSIBLE SELF \#1}

(Provide a detailed description of the self)

1. Why is this feared self important to you? 
2. What kind of things have you done, or not done, recently to avoid this feared self in the future?

3. Are you experiencing any challenges or obstacles to avoid this self?

4. Now, thinking back to when you first decided that this feared self was an important goal for the future: Can you identify an even, a personal realization, another person, or a particular influence that caused you to develop this possible self? (PLEASE DESCRIBE IN DETAIL):

5. To what extent does this possible self describe you now?

$\begin{array}{llllllll}1 & 2 & 3 & 4 & 5 & 6 & 7\end{array}$

Not at all Somewhat Very much

6. To what extent would you dislike this possible self to describe you in the future?

$\begin{array}{lllllll}1 & 2 & 3 & 4 & 5 & 6 & 7\end{array}$

Not at all Somewhat Very much

7. How important is it to you to avoid this possible self in the future?

$\begin{array}{llllllll}1 & 2 & 3 & 4 & 5 & 6 & 7\end{array}$

Not at all Somewhat $\quad$ Very much

8. How capable do you feel of avoiding this self in the future?

$\begin{array}{llllllll}1 & 2 & 3 & 4 & 5 & 6 & 7\end{array}$

Not at all Somewhat $\quad$ Very much

9. How likely do you think it is that you WILL avoid this possible self in the future?

$\begin{array}{lllllll}1 & 2 & 3 & 4 & 5 & 6 & 7\end{array}$

Not at all Somewhat Very much 


\section{FEARED POSSIBLE SELF \#2}

(Provide a detailed description of the self)

1. Why is this feared self important to you?

2. What kind of things have you done, or not done, recently to avoid this feared self in the future?

3. Are you experiencing any challenges or obstacles to avoid this self?

4. Now, thinking back to when you first decided that this feared self was an important goal for the future: Can you identify an even, a personal realization, another person, or a particular influence that caused you to develop this possible self? (PLEASE DESCRIBE IN DETAIL):

5. To what extent does this possible self describe you now?

$\begin{array}{lllllll}1 & 2 & 3 & 4 & 5 & 6 & 7\end{array}$

Not at all

Somewhat

Very much

6. To what extent would you dislike this possible self to describe you in the future?

$\begin{array}{llllllll}1 & 2 & 3 & 4 & 5 & 6 & 7\end{array}$

Not at all Somewhat Very much

7. How important is it to you to avoid this possible self in the future?

$\begin{array}{lllllll}1 & 2 & 3 & 4 & 5 & 6 & 7\end{array}$

Not at all

Somewhat

Very much

8. How capable do you feel of avoiding this self in the future?

$\begin{array}{llllllll}1 & 2 & 3 & 4 & 5 & 6 & 7\end{array}$

Not at all

Somewhat

Very much 
9. How likely do you think it is that you WILL avoid this possible self in the future?

1

Not at all
2

3
4

Somewhat
6 7

Very much

\section{FEARED POSSIBLE SELF \#3}

(Provide a detailed description of the self)

1. Why is this feared self important to you?

2. What kind of things have you done, or not done, recently to avoid this feared self in the future?

3. Are you experiencing any challenges or obstacles to avoid this self?

4. Now, thinking back to when you first decided that this feared self was an important goal for the future: Can you identify an even, a personal realization, another person, or a particular influence that caused you to develop this possible self? (PLEASE DESCRIBE IN DETAIL):

5. To what extent does this possible self describe you now?

$\begin{array}{llllllll}1 & 2 & 3 & 4 & 5 & 6 & 7\end{array}$

Not at all

Somewhat

Very much

6. To what extent would you dislike this possible self to describe you in the future?

1

2

3

4

5

6

7

Not at all

Somewhat

Very much

7. How important is it to you to avoid this possible self in the future?

1

2

3

4

5

6

7

Not at all

Somewhat

Very much 
8. How capable do you feel of avoiding this self in the future?

\begin{tabular}{llccccc}
1 & 2 & 3 & 4 & 5 & 6 & 7 \\
Not at all & \multicolumn{9}{c}{ Somewhat } & & & Very much
\end{tabular}

9. How likely do you think it is that you WILL avoid this possible self in the future?

\begin{tabular}{llccccc}
1 & 2 & 3 & 4 & 5 & 6 & 7 \\
Not at all & \multicolumn{9}{c}{ Somewhat } & & & Very much
\end{tabular}


Appendix D

Possible Selves Coding Schemes

01 Personal: includes references to personal attributes or attitudes, ("independent," "intelligent," or "harried," "dissatisfied with my life") and to philosophical or spiritual issues.

02 Physical: includes references to fitness ("in good shape"), attractiveness ("thin" or "fat"), or a physical problem (e.g., "disabled").

03 Abilities and Education: includes references to creative or artistic expression ("to be a good artist"), to education ("to have an advanced degree," "flunking out of school"), and to general knowledge ("becoming fluent in another language," being well-read").

04 Lifestyle: includes geographical references ("to live on the east coast"), references to living in a nursing home, and references to quality of life ("living a simpler lifestyle," "having children more far away").

05 Family: includes all references to marriage or divorce, spouse, grandparenting, relating to one's own parents, and family illness. Anything family related.

06 Relationships: includes all references to friendship ("being a sympathetic friend," "being alone and lonely") and opposite sex relationships not clearly indicated as family.

07 Occupation: includes all references to jobs ("having a job I truly enjoy," "having a boring job"), careers ("to be an effective therapist"), and retirement.

08 Material: includes all references to financial security ("self-supporting," "poor"), and to specific possessions ("having a medium-sized, comfortable home").

09 Success: includes all references to achieving goals ("to finish the story of my family," "to be a failure"), and to recognition or fame ("becoming a dominant authority in my field").

10 Social Responsibility: includes all references to volunteer work, community involvement, and activity relating to other social issues ("a leader in eliminating the treat of nuclear war").

11 Leisure: includes all references to travel or vacations ("traveling with my husband as semi-retirees"), hobbies and recreational sports ("a good tennis player and runner"), and other leisure time activities (e.g., "a music appreciator").

12 Health: includes all references to general health ("in poor health," "long-lived"), specific diseases ("having Parkinson's disease"), substance abuse ("being an alcoholic"). Anything pertaining to illness. 
13 Independence/Dependence: includes all references to being dependent on others for activities of daily living ("I couldn't take care of myself," "not being able to cook for myself"). A hoped-for self could include independence ("maintaining my independence"), feared selves could include not being a burden to others.

14 Death: includes any reference to personal death ("having a prolonged death," "having a terminal illness")

15 Bereavement: includes all references to death of a loved one ("losing my spouse," "widowed," "child's death").

16 Threats: includes all references to events which were perceived to be threatening to the individual ("being raped," "having my house broken into," being stranded on the highway with a broken down car").

17 Caregiving: includes explicit references to giving care or assistance to spouse (e.g., hoped-for self- "to continue caring for my wife" or feared self- "to be too sick to care for my husband"). Note that the last example makes reference to health, but is coded as caregiving because the reason she fears poor health is that she would no longer be caregiving for her husband.

18 Cognitive: includes all references to loss of cognitive functions or processes ("to loose my memory," "to become senile," "to loose my mind"). 
Appendix E

\section{Secondary Coding Scheme}

\section{Appearance possible selves}

Possible self domain Description

$0 \quad$ None

No explicit references to appearance or physical self.

1 Weight

Explicit references to body weight including concerns about body fat ("not weigh myself twice a day anymore", "I don't want to become obese", and "I want to lose some body fat").

2 Body image

Explicit references to body image (not related primarily to attractiveness or weight), including concerns about body shape ("I want to stay thin", "to be more curvy", and "be fit").

$3 \quad$ Dieting

Explicit references to activities directed at controlling one's weight ("I want to loose 23 pounds", "lose enough weight to fit into my skinny jeans", and "not eat too much carbs").

4 Exercise/activity

$5 \quad$ Attractiveness/beauty

Explicit references to sport activities ("to become a professional lacrosse player", and "to go to the gym three times a week").

Explicit references to attractiveness and external beauty (not including inner beauty) ("I want to feel beautiful", "to be sexy even after having three kids", and "I want to stay pretty and be featured in a fashion magazine").

6 Strength/Muscularity

Explicit references to body strength. The focus is on body strength and/or muscularity (or lack of strength and/or muscularity), not on the activities that led to that state ("I want to build on muscles in my lower body", "to stay fit", and "to get rid of my flabby arms").

7 Health problems/Personal health

Explicit references to personal health including concerns pertaining to the consequences of one's health on her appearance ("I am afraid to have diabetes if I don't lose weight", "to be able to carry a child in spite of my eating disorder", and "not having high cholesterol as a result of my weight").

8 Others

Other references that do no fit into the categories described above. 
Appendix F

PHYSICAL SELF-DESCRIPTION QUESTIONNAIRE

This is a chance to look at yourself. It is not a test. There are no right answers and everyone will have different answers. Be sure that your answers show how you feel about yourself. PLEASE DO NOT TALK ABOUT YOUR ANSWERS WITH ANYONE ELSE. We will keep your answers private and not show them to anyone.

The purpose of this study is to see how people describe themselves physically. In the following pages you will be asked to think about yourself physically; For example, how good looking you are, how strong you are, how good you are at sports, whether you exercise regularly, whether you are physically coordinated, whether you get sick very often and so forth. Answer each sentence quickly as you feel now. Please do not leave any sentence blank.

\section{Statement}

1 When I get sick I feel so bad that I cannot even get out of bed

2 I feel confident when doing coordinated movements

Several times a week I exercise or play hard enough to breathe

3 hard (to huff and puff)

4 I am too fat

5 Other people think I am good at sports

6 I am satisfied with the kind of person I am physically

7 I am attractive for my age

8 I am a physically strong person

9 I am quite good at bending, twisting, and turning my body

10 I can run a long way without stopping

11 Overall, most things I do turn out well I usually catch whatever illness (flu, virus, cold, etc.) is going 12 around
FALSE TRUE

$\begin{array}{llllll}1 & 2 & 3 & 4 & 5 & 6\end{array}$

$\begin{array}{llllll}1 & 2 & 3 & 4 & 5 & 6\end{array}$

$\begin{array}{llllll}1 & 2 & 3 & 4 & 5 & 6\end{array}$

$\begin{array}{llllll}1 & 2 & 3 & 4 & 5 & 6\end{array}$

$\begin{array}{llllll}1 & 2 & 3 & 4 & 5 & 6\end{array}$

$\begin{array}{llllll}1 & 2 & 3 & 4 & 5 & 6\end{array}$

$\begin{array}{llllll}1 & 2 & 3 & 4 & 5 & 6\end{array}$

$\begin{array}{llllll}1 & 2 & 3 & 4 & 5 & 6\end{array}$

$\begin{array}{llllll}1 & 2 & 3 & 4 & 5 & 6\end{array}$

$\begin{array}{llllll}1 & 2 & 3 & 4 & 5 & 6\end{array}$

$\begin{array}{llllll}1 & 2 & 3 & 4 & 5 & 6\end{array}$

$\begin{array}{llllll}1 & 2 & 3 & 4 & 5 & 6\end{array}$ 
13 Controlling movements of my body comes easily to me

14 I often do exercise or activities that makes me breathe hard

15 My waist is too large

16 I am good at most sports

17 Physically, I am happy with myself

18 I have a nice looking face

19 I have a lot of power in my body

20 My body is flexible

21 I would do well in a test of physical endurance and stamina

22 I don't have much to be proud of

23 I am sick so often that I cannot do all the things I want to do

24 I am good at coordinated movements

I get exercise or activity three or four times a week that makes

25 me huff and puff and lasts at least 30 minutes

26 I have too much fat on my body

27 Most sports are easy for me

28 I feel good about the way I look and what I can do physically

29 I am better looking than most of my friends

30 I am stronger than most people my age

31 My body is stiff and inflexible

32 I could jog 5 kilometres without stopping

33 I feel that my life is not very useful

34 I hardly ever get sick or ill

35 I can perform movements smoothly in most physical activities I do physically active things (like jogging, dancing, bicycling, 36 aerobics, gym, or swimming) at least three times a week $\begin{array}{llllll}1 & 2 & 3 & 4 & 5 & 6\end{array}$

$\begin{array}{llllll}1 & 2 & 3 & 4 & 5 & 6\end{array}$

$\begin{array}{llllll}1 & 2 & 3 & 4 & 5 & 6\end{array}$

$\begin{array}{llllll}1 & 2 & 3 & 4 & 5 & 6\end{array}$

$\begin{array}{llllll}1 & 2 & 3 & 4 & 5 & 6\end{array}$

$\begin{array}{llllll}1 & 2 & 3 & 4 & 5 & 6\end{array}$

$\begin{array}{llllll}1 & 2 & 3 & 4 & 5 & 6\end{array}$

$\begin{array}{llllll}1 & 2 & 3 & 4 & 5 & 6\end{array}$

$\begin{array}{llllll}1 & 2 & 3 & 4 & 5 & 6\end{array}$

$\begin{array}{llllll}1 & 2 & 3 & 4 & 5 & 6\end{array}$

$\begin{array}{llllll}1 & 2 & 3 & 4 & 5 & 6\end{array}$

$\begin{array}{llllll}1 & 2 & 3 & 4 & 5 & 6\end{array}$

$\begin{array}{llllll}1 & 2 & 3 & 4 & 5 & 6\end{array}$

$\begin{array}{llllll}1 & 2 & 3 & 4 & 5 & 6\end{array}$

$\begin{array}{llllll}1 & 2 & 3 & 4 & 5 & 6\end{array}$

$\begin{array}{llllll}1 & 2 & 3 & 4 & 5 & 6\end{array}$

$\begin{array}{llllll}1 & 2 & 3 & 4 & 5 & 6\end{array}$

$\begin{array}{llllll}1 & 2 & 3 & 4 & 5 & 6\end{array}$

$\begin{array}{llllll}1 & 2 & 3 & 4 & 5 & 6\end{array}$

$\begin{array}{llllll}1 & 2 & 3 & 4 & 5 & 6\end{array}$

$\begin{array}{llllll}1 & 2 & 3 & 4 & 5 & 6\end{array}$

$\begin{array}{llllll}1 & 2 & 3 & 4 & 5 & 6\end{array}$

$\begin{array}{llllll}1 & 2 & 3 & 4 & 5 & 6\end{array}$

$\begin{array}{llllll}1 & 2 & 3 & 4 & 5 & 6\end{array}$ 
37 I am overweight

38 I have good sports skills

39 Physically I feel good about myself

40 I am ugly

41 I am weak and have no muscles

42 My body parts bend and move in most directions well

43 I think I could run a long way without getting tired

44 Overall, I am no good

45 I get sick a lot

46 I find my body handles coordinated movements with ease

47 I do lots of sports, dance, gym, or other physical activities

48 My stomach is too big

49 I am better at sports than most of my friends

50 I feel good about who I am and what I can do physically

$51 \quad$ I am good looking

52 I would do well in a test of strength

53 I think I am flexible enough for most sports

I can be physically active for a long period of time without

54 getting tired

55 Most things I do, I do well

56 When I get sick it takes me a long time to get better

57 I am graceful and coordinated when I do sports and activities

I do sports, exercise, dance or other physical activities almost

58 every day

59 Other people think that I am fat

60 I play sports well $\begin{array}{llllll}1 & 2 & 3 & 4 & 5 & 6\end{array}$

$\begin{array}{llllll}1 & 2 & 3 & 4 & 5 & 6\end{array}$

$\begin{array}{llllll}1 & 2 & 3 & 4 & 5 & 6\end{array}$

$\begin{array}{llllll}1 & 2 & 3 & 4 & 5 & 6\end{array}$

$\begin{array}{llllll}1 & 2 & 3 & 4 & 5 & 6\end{array}$

$\begin{array}{llllll}1 & 2 & 3 & 4 & 5 & 6\end{array}$

$\begin{array}{llllll}1 & 2 & 3 & 4 & 5 & 6\end{array}$

$\begin{array}{llllll}1 & 2 & 3 & 4 & 5 & 6\end{array}$

$\begin{array}{llllll}1 & 2 & 3 & 4 & 5 & 6\end{array}$

$\begin{array}{llllll}1 & 2 & 3 & 4 & 5 & 6\end{array}$

$\begin{array}{llllll}1 & 2 & 3 & 4 & 5 & 6\end{array}$

$\begin{array}{llllll}1 & 2 & 3 & 4 & 5 & 6\end{array}$

$\begin{array}{llllll}1 & 2 & 3 & 4 & 5 & 6\end{array}$

$\begin{array}{llllll}1 & 2 & 3 & 4 & 5 & 6\end{array}$

$\begin{array}{llllll}1 & 2 & 3 & 4 & 5 & 6\end{array}$

$\begin{array}{llllll}1 & 2 & 3 & 4 & 5 & 6\end{array}$

$\begin{array}{llllll}1 & 2 & 3 & 4 & 5 & 6\end{array}$

$\begin{array}{llllll}1 & 2 & 3 & 4 & 5 & 6\end{array}$

$\begin{array}{llllll}1 & 2 & 3 & 4 & 5 & 6\end{array}$

$\begin{array}{llllll}1 & 2 & 3 & 4 & 5 & 6\end{array}$

$\begin{array}{llllll}1 & 2 & 3 & 4 & 5 & 6\end{array}$

$\begin{array}{llllll}1 & 2 & 3 & 4 & 5 & 6\end{array}$

$\begin{array}{llllll}1 & 2 & 3 & 4 & 5 & 6\end{array}$

$\begin{array}{llllll}1 & 2 & 3 & 4 & 5 & 6\end{array}$ 
61 I feel good about who I am physically

62 Nobody thinks that I am good looking

63 I am good at lifting heavy objects

64 I think I would perform well on a test measuring flexibility I am good at endurance activities like distance running,

65 aerobics, bicycling, swimming, or cross-country skiing

66 Overall, I have a lot to be proud of

I have to go to the doctor because of illness more than most

67 people my age

68 Overall, I am a failure

69 I usually stay healthy even when my friends get sick

70 Nothing I do ever seems to turn out right $\begin{array}{llllll}1 & 2 & 3 & 4 & 5 & 6\end{array}$

$\begin{array}{llllll}1 & 2 & 3 & 4 & 5 & 6\end{array}$

$\begin{array}{llllll}1 & 2 & 3 & 4 & 5 & 6\end{array}$

$\begin{array}{llllll}1 & 2 & 3 & 4 & 5 & 6\end{array}$

$\begin{array}{llllll}1 & 2 & 3 & 4 & 5 & 6\end{array}$

$\begin{array}{llllll}1 & 2 & 3 & 4 & 5 & 6\end{array}$

$\begin{array}{llllll}1 & 2 & 3 & 4 & 5 & 6\end{array}$

$\begin{array}{llllll}1 & 2 & 3 & 4 & 5 & 6\end{array}$

$\begin{array}{llllll}1 & 2 & 3 & 4 & 5 & 6\end{array}$

$\begin{array}{llllll}1 & 2 & 3 & 4 & 5 & 6\end{array}$ 


\section{Appendix G}

\section{EATING ATTITUDES TEST (EAT-26)}

This is a screening measure to help you determine whether you might have an eating disorder that needs professional attention. This screening measure is not designed to make a diagnosis of an eating disorder or take the place of a professional diagnosis or consultation. Please take the time to fill out the below form as accurately, honestly and completely as possible. All of your responses are confidential.

\section{Please circle a response for each of the following questions}

\begin{tabular}{|c|c|c|c|c|c|c|}
\hline & Always & Usually & Often & Sometimes & Rarely & Never \\
\hline $\begin{array}{l}\text { 1. Am terrified about being } \\
\text { overweight. }\end{array}$ & 3 & 2 & 1 & 0 & 0 & 0 \\
\hline $\begin{array}{l}\text { 2. Avoid eating when I am } \\
\text { hungry }\end{array}$ & 3 & 2 & 1 & 0 & 0 & 0 \\
\hline $\begin{array}{l}\text { 3. Find myself preoccupied with } \\
\text { food }\end{array}$ & 3 & 2 & 1 & 0 & 0 & 0 \\
\hline $\begin{array}{l}\text { 4. Have gone on eating binges } \\
\text { where I feel I may not be able to } \\
\text { stop }\end{array}$ & 3 & 2 & 1 & 0 & 0 & 0 \\
\hline $\begin{array}{l}\text { 5. Cut my food into small } \\
\text { pieces }\end{array}$ & 3 & 2 & 1 & 0 & 0 & 0 \\
\hline $\begin{array}{l}\text { 6. Aware of the calorie content } \\
\text { of foods I eat }\end{array}$ & 3 & 2 & 1 & 0 & 0 & 0 \\
\hline $\begin{array}{l}\text { 7. Particularly avoid food with } \\
\text { high carbohydrate content } \\
\text { (bread, rice, potatoes, etc.) }\end{array}$ & 3 & 2 & 1 & 0 & 0 & 0 \\
\hline $\begin{array}{l}\text { 8. Feel that others would prefer } \\
\text { if I ate more }\end{array}$ & 3 & 2 & 1 & 0 & 0 & 0 \\
\hline 9. Vomit after I have eaten & 3 & 2 & 1 & 0 & 0 & 0 \\
\hline $\begin{array}{l}\text { 10. Feel extremely guilty after } \\
\text { eating }\end{array}$ & 3 & 2 & 1 & 0 & 0 & 0 \\
\hline $\begin{array}{l}\text { 11. Am preoccupied with a } \\
\text { desire to be thinner }\end{array}$ & 3 & 2 & 1 & 0 & 0 & 0 \\
\hline $\begin{array}{l}\text { 12. Think about burning up } \\
\text { calories when I exercise }\end{array}$ & 3 & 2 & 1 & 0 & 0 & 0 \\
\hline $\begin{array}{l}\text { 13. Other people think I'm too } \\
\text { thin }\end{array}$ & 3 & 2 & 1 & 0 & 0 & 0 \\
\hline
\end{tabular}


14. Am preoccupied with the thought of having fat on my body

15. Take longer than others to eat my meals

16. Avoid foods with sugar in them

17. Eat diet foods

18. Feel that food controls my life

19. Display self-control around food

20. Feel that other pressure me to eat

21. Give too much time and thought to food

22. Feel uncomfortable after eating sweets

23. Engage in dieting behavior

24. Like my stomach to be empty

25 . Have the impulse to vomit after meals

26. Enjoy trying new rich foods

3

2

3

2

1

0

0

0

3

2

1

0

0

0

3

2

1

0

$0 \quad 0$

3

3

3

3

3

3

3

3

3

3

3

2

1

0

0

0

3

2

1

0

$0 \quad 0$

2

1

0

$0 \quad 0$

$2 \quad 1 \quad 0 \quad 0 \quad 0$

$2 \quad 1 \quad 0 \quad 0 \quad 0$

$2 \quad 1 \quad 0 \quad 0 \quad 0$

\section{Please respond to each of the following questions}

Have you gone on eating binges, eating much more than most people would eat under the circumstances, where you feel that you may not be able to stop?

No Yes

If yes, on average, how many times per month over the last 6 months?

Have you ever made yourself sick (vomited) to control your weight or shape? 
No Yes

If yes, on average, how many times per month over the last 6 months?

Have you ever used laxatives, diet pills or diuretics (water pills) to control your weight or shape?

No Yes

If yes, on average, how many times per month over the last 6 months?

Have you ever been treated for an eating disorder?

No Yes

If yes, when?

Have you recently thought of or attempted suicide?

No Yes

If yes, when? 


\section{Appendix $\mathrm{H}$}

\section{ROSENBERG SELF-ESTEEM SCALE}

Below is a list of statements dealing with your general feelings about yourself. If you strongly agree, circle SA. If you agree with the statement, circle $\mathbf{A}$. If you disagree, circle D. If you strongly disagree, circle SD

1. On the whole, I am satisfied with myself.

SA

2. At times, I think I am no good at all.

3. I feel that I have a number of good qualities.

4. I am able to do things as well as most other people.

5. I feel I do not have much to be proud of.

6. I certainly feel useless at times.

7. I feel that I'm a person of worth, at least on an equal plane with others.

8. I wish I could have more respect for myself.

9. All in all, I am inclined to feel that I am a failure.

10. I take a positive attitude toward myself.
SA

SA

SA

SA

SA

SA

SA

SA

SA
A

A

A

A

A

A

A

A

A

A

D

SD 